\title{
Idealised simulations of sting-jet cyclones
}

Article

Published Version

Baker, L. H., Gray, S. L. and Clark, P. A. (2014) Idealised simulations of sting-jet cyclones. Quarterly Journal of the Royal Meteorological Society, 140 (678). pp. 96-110. ISSN 1477-870X doi: https://doi.org/10.1002/qj.2131 Available at https://centaur.reading.ac.uk/33269/

It is advisable to refer to the publisher's version if you intend to cite from the work. See Guidance on citing.

Published version at: http://onlinelibrary.wiley.com/doi/10.1002/qj.2131/full

To link to this article DOI: http://dx.doi.org/10.1002/qj.2131

Publisher: Royal Meteorological Society

All outputs in CentAUR are protected by Intellectual Property Rights law, including copyright law. Copyright and IPR is retained by the creators or other copyright holders. Terms and conditions for use of this material are defined in the End User Agreement.

www.reading.ac.uk/centaur

\section{CentAUR}

Central Archive at the University of Reading

Reading's research outputs online 


\title{
RMetS
}

Royal Meteorological Society

\section{Idealised simulations of sting-jet cyclones}

\author{
L. H. Baker, ${ }^{\star}$ S. L. Gray and P. A. Clark \\ Department of Meteorology, University of Reading, UK \\ ${ }^{*}$ Correspondence to: L. H. Baker, Department of Meteorology, University of Reading, Earley Gate, \\ PO Box 243, Reading RG6 6BB, UK. E-mail: 1.h.baker@reading.ac.uk
}

An idealised modelling study of sting-jet cyclones is presented. Sting jets are descending mesoscale jets that occur in some extratropical cyclones and produce localised regions of strong low-level winds in the frontal fracture region. Moist baroclinic lifecycle (LC1) simulations are performed with modifications to produce cyclones resembling observed sting-jet cyclones.

A sting jet exists in the idealised control cyclone with similar characteristics to the sting jet in a simulation of windstorm Gudrun (a confirmed sting-jet case). Unlike in windstorm Gudrun, a low-level layer of strong moist static stability prohibits the descent of the strong winds from above the boundary layer to the surface in the idealised case. Conditional symmetric instability (CSI) exists in the cloud head and dissipates as the sting jet leaves the cloud head and descends. The descending, initially moist, sting-jet trajectories consistently have negative or near-zero saturated moist potential vorticity but moist static stability and inertial stability, consistent with CSI release; the moist static stability becomes negative during the period of most rapid descent, by which time the air is relatively dry implying conditional instability release is unlikely.

Sensitivity experiments show that the existence of the sting jet is robust to changes in the initial state, and that the initial tropospheric static stability significantly impacts the descent rate of the sting jet. Inertial and conditional instability are probably being released in the experiment with the weakest initial static stability. This suggests that sting jets can arise through the release of all three instabilities associated with negative saturated moist potential vorticity. While evaporative cooling occurs along the sting-jet trajectories, a sensitivity experiment with evaporation effects turned off shows no significant change to the wind strength or descent rate of the sting jet implying that instability release is the dominant sting-jet driving mechanism. Copyright (c) 2013 Royal Meteorological Society

Key Words: $\quad$ extratropical cyclone; sting jet; idealised; baroclinic lifecycle; windstorm; instability

Received 9 November 2012; Revised 4 February 2013; Accepted 6 February 2013; Published online in Wiley Online Library

Citation: Baker LH, Gray SL, Clark PA. 2013. Idealised simulations of sting-jet cyclones. Q. J. R. Meteorol. Soc. DOI:10.1002/qj.2131

\section{Introduction}

Sting jets occur in some severe extratropical cyclones (here termed sting-jet cyclones) and can result in regions of localised strong, and potentially very damaging, surface winds. The sting jet is a transient mesoscale jet of air that originates at mid-levels within the cloud head, descending from the tip of the cloud head to the top of the boundary layer, and in some cases can generate localised very strong surface gusts. To date, detailed analysis of sting-jet storms has been limited to only a small number of specific cases. These cases are the Great Storm of 16-17 October 1987 


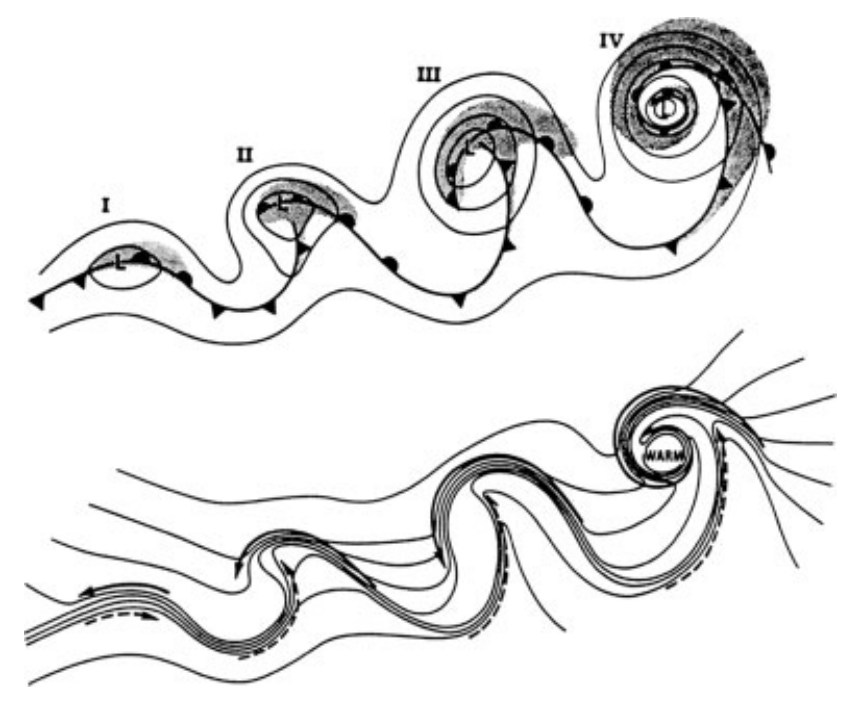

Figure 1. Schematic diagram of the Shapiro-Keyser conceptual model of cyclone development, from Shapiro and Keyser (1990), Figure 10.27. The four stages are (I) incipient frontal cyclone, (II) frontal fracture, (III) bentback front and frontal T-bone, and (IV) warm core frontal seclusion. The upper panel shows sea-level pressure (solid lines), fronts (bold lines) and cloud signature (shaded); the lower panel shows surface temperature (solid lines), and cold and warm air flows (solid and dashed arrows, respectively).

(Browning, 2004; Browning and Field, 2004; Clark et al., 2005), windstorm Jeanette on 27 October 2002 (Parton et al., 2009), windstorm Gudrun on 7-8 January 2005 (Baker, 2009; Gray et al., 2011) and windstorm Anna on 26 February 2002 (Martínez-Alvarado et al., 2010; Gray et al., 2011). Parton et al. (2010) provided the first climatology of sting-jet storms, showing that nine out of 117 mesoscale strong wind events identified from seven years of data from the Mesosphere-Stratosphere-Troposphere (MST) wind profiling radar in Aberystwyth, Wales, were sting-jet cyclones. Martínez-Alvarado et al. (2012) produced a climatology of sting-jet cyclones using reanalysis data from the European Centre for Medium-range Weather Forecasts, showing that $25-33 \%$ of the 100 most intense cyclones over the North Atlantic in the period 1989-2009 were sting-jet cyclones. Due to the potential destruction caused by the strong winds associated with the sting jet, it is of interest to determine the important mechanisms leading to sting jets.

Here we present idealised model simulations of sting-jet cyclones. The purpose of this study is to provide a more generalised perspective to add to the very small number of specific case analyses in the existing literature. The design of the idealised simulations enables controlled sensitivity analysis which is used to determine the important processes leading to sting jets.

A feature common to all the analysed cases is that they developed according to the Shapiro and Keyser (1990) conceptual model of cyclone development (Figure 1). The Shapiro-Keyser model has four stages: (I) incipient frontal cyclone, (II) frontal fracture, (III) bent-back front and frontal T-bone, and (IV) warm core frontal seclusion. The sting jet is a transient mesoscale jet that descends from the tip of the cloud head and produces a region of strong winds in the frontal fracture region (the region of slack wet-bulb potential temperature $\left(\theta_{\mathrm{w}}\right)$ gradient ahead of the bent-back front) near to the top of the boundary layer (Figure 2). These strong low-level winds occur at approximately stage III of the Shapiro-Keyser model (Clark et al., 2005; Parton et al., 2009). The sting jet is distinct from the longer-lived

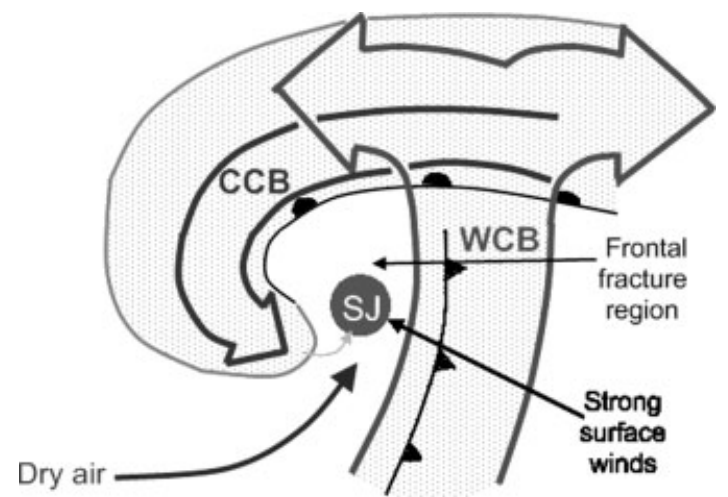

Figure 2. Conceptual picture of a sting-jet cyclone, with key features labelled. Fronts are labelled with standard symbols. Regions of cloud are shown stippled.

low-level jets associated with the warm and cold conveyor belts which flow along the primary cold front and bent-back front.

The definition of a sting jet used here is derived from the analysis by Clark et al. (2005) of the sting jet in the Great Storm. Windstorms Gudrun, Jeanette and Anna also contained sting jets that satisfied these criteria (Baker, 2009; Parton et al., 2009; Martínez-Alvarado et al., 2010), which can be summarised as follows:

1. Originates at mid-levels $(600-800 \mathrm{hPa})$ within the cloud head;

2. Descends along a sloping surface of constant $\theta_{\mathrm{w}}$;

3. Accelerates and reduces in relative humidity $(\mathrm{RH})$ during descent;

4. Results in strong winds near the top of the boundary layer;

5. Is distinct from the low-level jets associated with the warm and cold conveyor belts.

The case-studies of sting-jet cyclones have been prompted by associated strong observed near-surface gusts. However, turbulent momentum transport in the boundary layer, which can bring the high-momentum air down from the top of the boundary layer to the surface, is parametrised in models. Therefore, the occurrence of strong near-surface gusts is not included as a sting-jet criterion here; instead only the wind strength near the top of the boundary layer (around $800-850 \mathrm{hPa}$ ) is considered.

Two key processes have been hypothesized as being important in the development of sting jets: the release of conditional symmetric instability (CSI) and evaporative cooling. CSI is a moist instability that can occur in an atmosphere that is stable to horizontal displacements (inertially stable) and stable to vertical displacements (convectively stable), but unstable to slantwise displacements. It is defined by Bennetts and Hoskins (1979) and Emanuel (1983a,b) and reviewed by Schultz and Schumacher (1999), although the theory was developed in earlier work (as discussed in the review of the work of Kleinschmidt by Thorpe, 1992). The release of CSI results in slantwise convection and is often associated with banding in the cloud heads of extratropical cyclones. Studies of sting-jet cyclones by (Parton et al., 2009), Martínez-Alvarado et al. (2011) and Gray et al. (2011), using diagnostics based on slantwise convective available potential energy (SCAPE) and moist potential vorticity (MPV), have shown evidence that the release of CSI contributes to the 
development of sting jets. Evaporative cooling was hypothesized by Browning (2004) to enhance the strong winds associated with the sting jet both by intensifying the slantwise circulations associated with CSI release, and by reducing the static stability in the dry slot ahead of the cloud-head tip which enables turbulent mixing of the high-momentum air to the surface. Martinez-Alvarado et al. (2011) developed a diagnostic for sting jets based on both CSI and evaporative cooling, using the release of downdraught slantwise convective available potential energy (DSCAPE); the release of DSCAPE requires saturation of the sting-jet air maintained by evaporation of rain or snow falling into it from above.

While case-studies are useful for investigating the properties of sting jets and determining features common to sting-jet cyclones, there is need for the more generalised study presented here using an idealised model to understand the mechanisms leading to sting jets and to understand further the dynamics of the sting jet. We note that there exists one article in the published literature, Cao (2009), which discusses a feature in an idealised simulation that Cao calls a sting jet. However, the resolution of his simulation (50 km horizontal grid spacing and just 14 vertical levels) is not sufficient to resolve CSI circulations (Persson and Warner, 1993). Furthermore, the feature discussed does not, as far as one can tell from the evidence presented, satisfy the sting-jet definition used in this article and earlier articles cited above, but instead appears to be the leading edge of the cold conveyor belt as it wraps around the low centre.

The idealised simulations here are based on the dry baroclinic lifecycle simulations of Thorncroft et al. (1993). Their simulations were designed to examine two distinct observed types of nonlinear baroclinic wave development, termed 'anticyclonic' (LC1) and 'cyclonic' (LC2) due to the direction of wrap-up of the resulting upper-level potential vorticity. Both were produced by applying a zonal wavenumber 6 perturbation to a baroclinically unstable midlatitude jet on the sphere. The LC2 case had cyclonic barotropic shear applied to the initial jet, resulting in an additional westerly wind component to the south of the jet and an easterly component to the north; the LC1 case had no barotropic shear. The cyclones resulting from the LC1 simulations became meridionally elongated, with a bentback warm front which formed a T-bone and later a frontal fracture with the relatively stronger cold front. The LC2 simulations produced more zonally elongated cyclones with stronger warm fronts and weaker cold fronts, and developed a frontal occlusion rather than frontal fracture. Shapiro et al. (1999) classified the LC1 cyclone development as Shapiro-Keyser type, while the LC2 development resembled the classical Norwegian cyclone development described by Bjerknes and Solberg (1922).

The simulations here are therefore based on the LC1 simulations of Thorncroft et al. (1993) but with the addition of moisture and a boundary layer, and with other modifications (described later) made to the initial parameters to produce a basic state closer to that observed in a sting-jet cyclone. Controlled sensitivity testing of the idealised cyclone is performed by modifying the basic state to determine the effects on both the structure and development of the resulting cyclone and properties of the sting jet (including its generation mechanisms). One simulation is run with microphysical diabatic cooling effects turned off to determine the importance of evaporation in enhancing or causing the sting jet. A dry run is also performed to confirm that the sting jet results from moist processes.

The idealised cyclone simulations are compared to an observed sting-jet cyclone, windstorm Gudrun. The sting jet in this windstorm resulted in $45 \mathrm{~m} \mathrm{~s}^{-1}$ winds near the top of the boundary layer. More detailed analyses of this case can be found in Baker (2009) and Gray et al. (2011).

The remainder of this article is structured as follows. The model, experimental set-up and diagnostics used are described in section 2. A description and analysis of the control cyclone are given in section 3 , including comparison with windstorm Gudrun, and results from the sensitivity analysis are given in section 4 . Finally, the discussion and conclusions are given in section 5 .

\section{Methodology}

\subsection{Model}

The numerical modelling was performed using the Met Office Unified Model (MetUM) Version 6.1. The MetUM is an operational finite-difference model which solves the non-hydrostatic, fully compressible, deep-atmosphere dynamical equations with a semi-Lagrangian, semi-implicit integration scheme (Davies et al., 2005). The equations are discretized using a horizontally staggered Arakawa C-grid and a terrain-following hybrid-height vertical coordinate with Charney-Phillips grid staggering. Parametrisations of physical processes in the model include long-wave and shortwave radiation (Edwards and Slingo, 1996), convection (Gregory and Rowntree, 1990), cloud microphysics and large-scale precipitation (Wilson and Ballard, 1999), and boundary-layer mixing (Lock et al., 2000).

\subsection{Model set-up}

The baroclinic lifecycle simulations described here were performed using the idealised configuration of the MetUM. The idealised configuration allows the option of including, or not including, any of the physical parametrisations described in section 2.1, and the option of running the simulation with or without moisture. Both dry and moist simulations have been performed. The physics parametrisations used in previous studies of simulated sting-jet cases with the MetUM (Baker, 2009; Martínez-Alvarado et al., 2010; Gray et al., 2011) were used in the idealised simulations, with the exception of radiation which was not included since it caused instability to develop in the southern part of the domain. While we cannot prove that the inclusion of radiation would not have a significant effect on cyclone development, this is a reasonable assumption given the short length (a few days) of our simulations.

The simulations were performed using spherical geometry on a periodic channel configuration. This is in contrast to previous idealised studies of extratropical cyclone development using the MetUM (Beare, 2007; Boutle et al., 2010) which used a rectangular grid with Cartesian geometry and a constant Coriolis parameter. The choice to use spherical geometry over Cartesian geometry is motivated by the studies of Whitaker and Snyder (1993) and Balasubramanian and Garner (1997), which showed that using an LC1 set-up in Cartesian geometry simulations produced stronger cyclones and weaker anticyclones, which 
in fact resembled the LC2 simulations of Thorncroft et al. (1993).

\subsection{Initial conditions}

The initial set-up is based on the dry LC1 set-up of Polvani and Esler (2007), which was designed to closely resemble the simulations in Thorncroft et al. (1993). As well as including moisture, additional changes have been made to the jet structure to produce cyclones more similar to observed sting-jet cases.

The basic state is a westerly zonal jet given by the equation

$$
u(\phi, z)=U_{0} F(\phi) G(z)
$$

where $\phi$ is latitude, $z$ is height and $U_{0}=45 \mathrm{~m} \mathrm{~s}^{-1}$ is the jet maximum. The functions $F(\phi)$ and $G(z)$ are given by

$$
F(\phi)=\left[\sin \left\{\pi \sin ^{2}\left(\frac{\pi}{2} \frac{\phi-\phi_{\mathrm{S}}}{\phi_{\mathrm{N}}-\phi_{\mathrm{S}}}\right)\right\}\right]^{3}
$$

and

$$
G(z)=\frac{z}{z_{\mathrm{T}}} \exp \left[\delta\left\{1-\left(\frac{z}{z_{\mathrm{T}}}\right)^{\frac{1}{\delta}}\right\}\right]
$$

where $\phi_{\mathrm{N}}$ and $\phi_{\mathrm{S}}$ determine the width of the jet, $\delta$ controls the vertical gradient of wind shear and $z_{\mathrm{T}}$ is the tropopause height. These constants have the values $\phi_{\mathrm{S}}=15^{\circ} \mathrm{N}, \phi_{\mathrm{N}}=85^{\circ} \mathrm{N}, \delta=0.2$ and $z_{\mathrm{T}}=10 \mathrm{~km}$. This gives a jet centred at $50^{\circ} \mathrm{N}$ with wind speed decreasing from there towards the Equator and North Pole (Figure 3(a)). In the vertical, the wind speed increases from zero at the surface to a maximum $U_{0}$ at the tropopause, and then decreases upwards through the stratosphere. The values $\phi_{\mathrm{S}}=0^{\circ} \mathrm{N}, \phi_{\mathrm{N}}=90^{\circ} \mathrm{N}, \delta=0.5$ and $z_{\mathrm{T}}=13 \mathrm{~km}$ were used by Polvani and Esler (2007) and running with these initial conditions produced similar results to their LC1 simulations. However, comparison with real sting-jet cyclones, in particular windstorm Gudrun, motivated the changes to the initial conditions to move the jet further north, make the jet narrower, and lower the tropopause height.

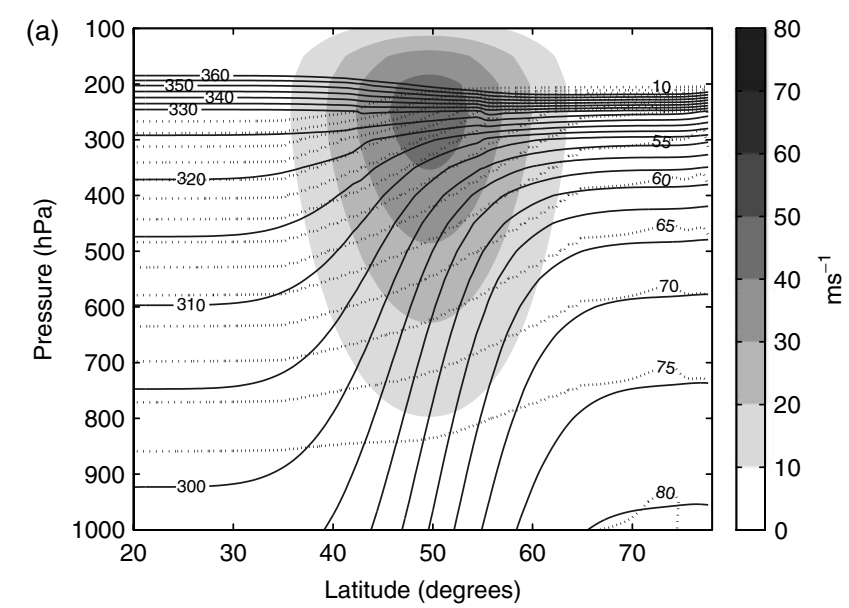

The horizontal temperature profile and pressure field are derived using classical hydrostatic, shallow-atmosphere thermal wind balance. The vertical variation in temperature is defined by the static stability, which is set as constant values throughout the troposphere and stratosphere (given by $\partial \theta /\left.\partial z\right|_{\text {trop }}=0.003 \mathrm{~K} \mathrm{~m}^{-1}$ and $\partial \theta /\left.\partial z\right|_{\text {strat }}=0.016 \mathrm{~K} \mathrm{~m}^{-1}$, respectively).

The resulting jet structure shown in Figure 3(a) can be compared with Figure 3(b), an equivalent profile for windstorm Gudrun several hours before its genesis. There are four key differences between these two jets:

1. Jet strength. The idealised set-up has a considerably weaker jet maximum: $45 \mathrm{~m} \mathrm{~s}^{-1}$ compared with $80 \mathrm{~m} \mathrm{~s}^{-1}$ in the real case. The jet maximum in the real case appears to be due to a jet streak and not representative of the mean zonal jet strength that the idealised set-up was designed to model.

2. Jet structure. The idealised jet is wider and located slightly further south, centred around $50^{\circ} \mathrm{N}$ compared with $58^{\circ} \mathrm{N}$ in the real case.

3. Meridional temperature gradient. The wind speed in the idealised jet decreases to zero at the surface while the real case has relatively strong winds extending down to low levels; consequently the idealised case has a stronger meridional temperature gradient at low levels than the real case. The weak meridional temperature gradient in the real case and relatively high midlatitude temperatures are due to the location of this section in the east Atlantic, compared with the zonal mean jet represented in the idealised simulation. Since all documented sting-jet cases so far have occurred in this region, it is possible that this temperature structure is important.

4. Available moisture. The lower temperatures at midlatitudes in the idealised case will reduce the amount of available moisture, enabling less cloud formation.

It would not be possible to address these differences without making substantial changes to the analytical configuration of the background state, such that it would no longer resemble the LC1 set-up. Despite these differences in the structure of the jets, this LC1-based set-up does go on to exhibit sting-jet behaviour.

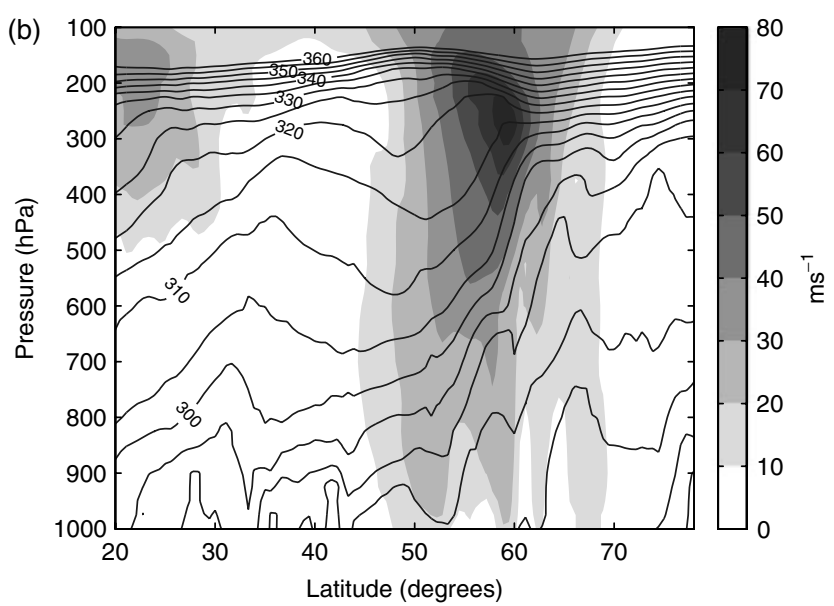

Figure 3. (a) Initial jet set-up for the moist control cyclone. Zonal winds ( $\mathrm{m} \mathrm{s}^{-1}$, shading), potential temperature (solid contours every $5 \mathrm{~K}$ upto $360 \mathrm{~K}$ ) and RH (dotted contours every 5\%). (b) MetUM global model forecast valid at 1600 UTC on 7 January 2005 (from an operational analysis at 0900 UTC on 7 January 2005), several hours before the genesis of windstorm Gudrun. Contouring is as (a), but with RH omitted for clarity. 
A balancing stage of several timesteps duration is needed to allow the model to adjust to the imposed jet, since the non-hydrostatic, deep-atmosphere model's definition of balance differs in detail from that used analytically. The initial jet set-up and balancing stages are performed on a large limited-area domain $\left(80^{\circ}\right.$ west-east by $70^{\circ}$ north-south) with fixed lateral boundaries at $10^{\circ} \mathrm{N}$ and $80^{\circ} \mathrm{N}$. After this, the data are reconfigured onto a smaller limited-area domain $\left(45^{\circ}\right.$ west-east by $66^{\circ}$ north-south), with east-west periodic boundaries and fixed north and south boundaries at $12^{\circ} \mathrm{N}$ and $78^{\circ} \mathrm{N}$, chosen to be far enough from the jet that they would not interfere with cyclone development.

To initiate baroclinic growth, a small temperature perturbation is applied following the method used by Polvani and Esler (2007). The perturbation is of the form

$$
T^{\prime}(\lambda, \phi)=T_{\mathrm{p}} \cos (m \lambda)\left[\operatorname{sech}\left\{m\left(\phi-\phi_{\mathrm{C}}\right)\right\}\right]^{2},
$$

where $\lambda$ is latitude, $m$ is the zonal wave number, $\phi_{C}=50^{\circ}$ is the latitude of the jet centre and $T_{\mathrm{p}}=1 \mathrm{~K}$. Here a wave number $m=8$ is used, and hence the $45^{\circ}$ west-east length of the domain was chosen to prevent upscale impact of the perturbation. This wave number was chosen to generate cyclones with a smaller length-scale (more consistent with scales of real sting-jet cyclones) than those generated by Polvani and Esler (2007) and Thorncroft et al. (1993). The resulting perturbation is independent of height, with a maximum value of $1 \mathrm{~K}$ at $50^{\circ} \mathrm{N}$.

Moisture is added by specifying a $\mathrm{RH}$ profile designed to be consistent with a climatological mean $\mathrm{RH}$ distribution. The distribution is given by

$$
R H(\phi, z)= \begin{cases}R H_{0}\left\{1-0.9\left(\frac{z}{z_{\mathrm{T}}}\right)^{\alpha} R(\phi)\right\} & z \leq z_{\mathrm{T}} \\ 0.0625 R H_{0} & z>z_{\mathrm{T}}\end{cases}
$$

where the maximum $\mathrm{RH}\left(\mathrm{RH}_{0}\right)$ is chosen to be $80 \%$ and $\alpha=1.25$ consistent with the value used by Weisman and Klemp (1982) in a similar set-up designed to give conditions for midlatitude convection. These equations are based on the moisture profile used by Tan et al. (2004). The latitudedependent term $R(\phi)$ is given by

$$
R(\phi)= \begin{cases}1 & \phi<\phi_{1} \\ 1-0.5 \frac{\phi-\phi_{1}}{\phi_{2}-\phi_{1}} & \phi_{1}<\phi<\phi_{2} \\ 0.5 & \phi>\phi_{2}\end{cases}
$$

where $\phi_{1}$ and $\phi_{2}$ are chosen to be $35^{\circ} \mathrm{N}$ and $65^{\circ} \mathrm{N}$, resulting in $\mathrm{RH}$ increasing polewards across the width of the jet. The RH decreases with height through the troposphere, from a maximum of just over $80 \%$ at the surface to around $25 \%$ at the tropopause, and decreases sharply above the tropopause (Figure 3(a)).

\subsection{Resolution}

Previous baroclinic lifecycle studies using the MetUM (Beare, 2007; Boutle et al., 2010) used a resolution of $0.4^{\circ}$ horizontal grid spacing and 38 vertical model levels. While this is sufficient to study the large-scale features of wave development, it is insufficient to resolve small and mesoscale features such as CSI and sting jets (Persson and Warner, 1993; Clark et al., 2005). The idealised simulations here were run for 8 days with $0.4^{\circ}$ horizontal grid spacing and 38 vertical levels, with lid around $39 \mathrm{~km}$. A higherresolution simulation was also produced by reconfiguring to $0.1^{\circ}$ horizontal grid spacing and 76 vertical levels at $48 \mathrm{~h}$ into the simulation. The additional vertical levels were inserted between the original 38, giving a mid-troposphere model level spacing of $200-300 \mathrm{~m}$. This is comparable to the resolution used in previous studies of sting-jet cyclones, e.g. Gray et al. (2011) used $0.11^{\circ}$ horizontal grid-spacing and the same 76 vertical levels used here. Comparison between low- and high-resolution simulations shows little difference in the large-scale cyclone structure and development (not shown).

\subsection{Analysis techniques}

As in previous studies, sting jets are diagnosed using trajectory calculations. The trajectory calculations were performed using the trajectory code of Wernli and Davies (1997). Hourly model data were used and interpolated from model levels to pressure levels every $25 \mathrm{hPa}$. The trajectory calculation used a $30 \mathrm{~min}$ timestep.

As described in section 1 , there is evidence that CSI has a role in the development of sting jets. Saturated moist potential vorticity $\left(\mathrm{MPV}^{*}\right)$ is commonly used as a diagnostic for CSI, defined as

$$
\mathrm{MPV}^{*}=\frac{1}{\rho} \zeta \cdot \nabla \theta_{\mathrm{e}}^{*}
$$

where $\rho$ is density, $\zeta$ is the absolute vorticity and $\theta_{\mathrm{e}}^{*}$ is the saturated equivalent potential temperature. $\mathrm{MPV}^{*}$ is negative in conditionally unstable regions. CSI exists where $\mathrm{MPV}^{*}$ is negative and the atmosphere is inertially and conditionally stable, that is where $\zeta$ and the saturated moist static stability $\left(N_{m}^{2}\right.$, defined as in Durran and Klemp, 1982) are positive. CSI can be released only in saturated air, and we apply the criterion $R H>90 \%$. These conditions are used here to determine the distribution of so-called CSI points. We use the full winds rather than geostrophic winds to calculate CSI, as in Gray et al. (2011), since the full winds are more representative than the geostrophic winds in curved flows, such as the cloud head (Gray and Thorpe, 2001; Novak et al., 2004).

\subsection{Description of the sensitivity experiments}

Sensitivity experiments were performed to find the setup that produced a cyclone most similar to a real sting-jet case (windstorm Gudrun). Simulations were performed with different values of the initial jet maximum $U_{0}$, the initial tropospheric vertical potential temperature gradient $\partial \theta /\left.\partial z\right|_{\text {trop }}$ (which controls the tropospheric static stability, $N_{\text {trop }}^{2}$ ), and the initial stratospheric vertical potential temperature gradient $\partial \theta /\left.\partial z\right|_{\text {strat }}$. All these runs produced cyclones with sting jet features. It was found that changing $\partial \theta /\left.\partial z\right|_{\text {trop }}$ had the greatest effect on the strength and descent rate of the resulting sting jet, and we therefore only discuss these runs in the sensitivity analysis in section 4 . The sting jet in the case with $\partial \theta /\left.\partial z\right|_{\text {trop }}=0.003 \mathrm{~K} \mathrm{~m}^{-1}$ was found to resemble the sting jet in simulated windstorm Gudrun most closely. We therefore refer to this as the control cyclone and give a detailed analysis of this case in section 3 . 
Table 1. Summary of the parameter values used in the initial set-up of the different runs.

\begin{tabular}{lccc}
\hline Run name & $U_{0}\left(\mathrm{~m} \mathrm{~s}^{-1}\right)$ & $\partial \theta /\left.\partial z\right|_{\text {trop }}\left(\mathrm{K} \mathrm{m}^{-1}\right)$ & $R H_{0}(\%)$ \\
\hline Control & 45 & 0.003 & 80 \\
Dry & 45 & 0.003 & 0 \\
NT50 & 45 & 0.005 & 80 \\
NT40 & 45 & 0.004 & 80 \\
NT35 & 45 & 0.0035 & 80 \\
NT25 & 45 & 0.0025 & 80 \\
\hline
\end{tabular}

A dry run was also performed to compare the largescale structure to previous LC1 simulations and to assess the importance of moisture. To investigate the role of evaporation, one run was performed in which the microphysical diabatic cooling processes (namely the evaporation of melting snow and rain) were turned off during the period of time that the sting jet in the moist control simulation was descending.

The initial set-up of each of the experiments is summarised in Table 1.

The parameters derived from each simulation are as follows:

- $u_{\max }$ : The largest value of the frontal fracture wind maximum, defined as the maximum wind speed near to the top of the boundary layer attributed to the descending sting jet. This maximum occurs at different times for different experiments due to variations in the development rates of the cyclones, but is located at either $850 \mathrm{hPa}$ or $825 \mathrm{hPa}$ in all cases. $u_{\max }$ is used as a measure of the strength of the sting jet.

- $\Delta p / \Delta t$ : The average descent rate of the trajectories. This is defined as the pressure change during the descent period of the trajectories, computed as the difference between the mean pressure of the trajectories at the end of descent and the mean pressure at the start of descent $(\Delta p)$ divided by the time over which the trajectories descend $(\Delta t)$. The period of descent is different for different experiments. This is also used as a measure of the strength of the sting jet.

- $u_{\mathrm{CCB}}$ : The maximum wind speed of the cold conveyor belt (CCB) at the tip of the cloud head at the same time and pressure level as the maximum sting-jet wind strength $u_{\max }$. Note that this is not necessarily the maximum CCB wind strength, which may occur earlier or later, and at a lower level, but here it is most useful to compare the CCB and sting-jet wind strengths at the same time.

- $\sigma_{\text {Eady }}$ :The theoretical dry Eady growth rate, calculated using the equation for the Eady growth rate

$$
\sigma_{\max }=0.31 \frac{f U_{0}}{N_{\text {trop }} z_{\mathrm{T}}}
$$

using values from the initial conditions.

- Eddy kinetic energy (EKE): This was calculated using model output from the low-resolution simulations, interpolated onto pressure levels, as

$$
\begin{aligned}
\mathrm{EKE}= & \frac{1}{2 g(n x n y n p)} \\
& \times \sum_{i, j, k=1}^{n x, n y, n p}\left\{\left(u_{i, j, k}-<u_{j, k}>\right)^{2}\right. \\
& \left.\quad+\left(v_{i, j, k}-<v_{j, k}>\right)^{2}\right\}
\end{aligned}
$$

over the whole horizontal domain, where $<>$ denotes the zonal mean, $n x$ and $n y$ are the numbers of gridpoints in the $x$ and $y$ directions, respectively, $n p$ is the number of pressure levels and $g$ is the acceleration due to gravity, taken as $g=9.81 \mathrm{~m} \mathrm{~s}^{-2}$.

- $\sigma_{\mathrm{EKE}}$ : The calculated growth rate, computed as

$$
\sigma_{\mathrm{EKE}}=\frac{1}{2} \frac{\Delta\{\ln (\mathrm{EKE})\}}{\Delta t}
$$

between times $t_{1}$ and $t_{2}$, where $t_{1}=0.16 t_{\mathrm{EKE}-\max }$, $t_{2}=0.4 t_{\mathrm{EKE}-\max }$, and $t_{\mathrm{EKE}-\max }$ is the time of the peak in EKE. These times were chosen to select the time period of the linear growth phase and were found to be appropriate for all the modelled cyclones.

\section{Control simulation}

\subsection{Large-scale development}

In both the dry and moist control simulations, the largescale baroclinic wave development compares well with the LC1 simulations of Thorncroft et al. (1993). A key difference, by design, is the length-scale of the cyclones, with the cyclones produced here spanning around $20-25^{\circ}$ (e.g. Figure 6(a)) compared with around $30^{\circ}$ in Thorncroft et al. (1993). The control simulations are more comparable to model simulations of windstorm Gudrun (around 15-20 Figure 6(b)) and other observed sting-jet cyclones (e.g. the Great Storm and windstorm Anna; Figure 1 of Gray et al., 2011).

Figure 4 shows the domain-averaged EKE for the lowresolution dry and moist control simulations. The peak in EKE in the dry simulation occurs just after day 5, while the peak in the moist simulation occurs around $12 \mathrm{~h}$ earlier. In both cases the peak occurs earlier than in the Polvani and Esler (2007) and Thorncroft et al. (1993) simulations which peaked at around day 7 . The maximum EKE reached in the dry run is $9.2 \times 10^{5} \mathrm{~J} \mathrm{~m}^{-2}$, and in the moist run is $13.7 \times 10^{5} \mathrm{~J} \mathrm{~m}^{-2}$. These values can be compared with the peak EKE values in the Thorncroft et al. (1993) LC1 simulation (around $10.5 \times 10^{5} \mathrm{~J} \mathrm{~m}^{-2}$ ) and the highest resolution Polvani and Esler (2007) simulation (around $9 \times 10^{5} \mathrm{~J} \mathrm{~m}^{-2}$ ). Higher peak EKE values in moist than in dry LC1 simulations were also found by Boutle et al. (2010). In the moist control simulation, a second local maximum in EKE occurred shortly before day 7. Analysis of the frontal structure at this time (not shown) shows that this is due to secondary cyclone development upstream of the main cyclone.

\subsection{Comparison of the moist cyclone with a real sting-jet cyclone}

We now consider the high-resolution control simulation. 


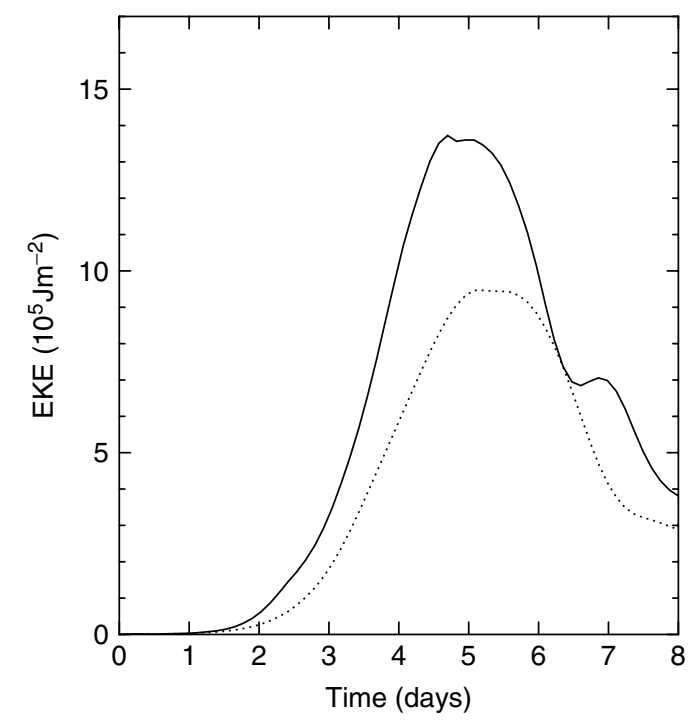

Figure 4. Time series of the domain-averaged EKE, averaged over pressure levels from 1000 to $50 \mathrm{hPa}$ ( $50 \mathrm{hPa}$ pressure spacing), for the moist control (solid line) and dry (dashed line) low-resolution simulations.

While the moist control cyclone develops more rapidly than the LC1 cyclones of Thorncroft et al. (1993), its development is considerably slower than the development of observed sting-jet cyclones. Figure 5 shows the cyclone at three times corresponding to the development Stages II-IV of the Shapiro-Keyser model (Stage I is not shown since it occurred before day 2 and therefore before reconfiguring to high resolution). The time period between Stage II and Stage IV is around $20 \mathrm{~h}$, which is considerably longer than the time between the equivalent stages in windstorm Gudrun (10 h; Figure $4(\mathrm{~b}-\mathrm{d})$ of Baker, 2009).

The frontal fracture occurs at day 2 hour 6 (Figure 5(a)). The cloud head by this time has become more elongated east-west than the cloud head in windstorm Gudrun (Figure 5(a) compared with Figure 4(b) of Baker, 2009). We hypothesize that this is because $\mathrm{RH}$ is initially zonally distributed, in contrast to real situations which may initially be associated with a more localised region of warm moist air. By day 2 hour 20, the bent-back warm front has formed (Figure 5(b)). At day 3 hour 2, Stage IV occurs, and a warm seclusion and hooked cloud head can be seen (Figure 5(c)).

\subsection{Identification of strong low-level winds}

In the moist control cyclone, a localised wind maximum exists near the top of the boundary layer within the frontal fracture region (here between the 275 and $276 \mathrm{~K} \theta_{\mathrm{w}}$ contours) where sting jets occur, at day 2 hour 20 (Figure 6(a)). The maximum wind strength associated with this region is $27 \mathrm{~m} \mathrm{~s}^{-1}$ (shown more clearly in Figure 6(c)). This is relatively weak compared to the wind maxima associated with the warm conveyor belt (WCB; further to the east, maximum winds greater than $30 \mathrm{~m} \mathrm{~s}^{-1}$ ) and CCB (located on the cold side of the warm front, maximum winds of $30 \mathrm{~m} \mathrm{~s}^{-1}$, but note that this jet is going against the direction of travel of the cyclone, so is stronger in a system-relative sense). Figure 6(b) shows an equivalent plot to Figure 6(a) for windstorm Gudrun at the time when the sting jet was identified. The sting jet in windstorm Gudrun has a maximum wind strength of $44 \mathrm{~m} \mathrm{~s}^{-1}$. Note that this much higher wind speed than the frontal fracture wind maximum
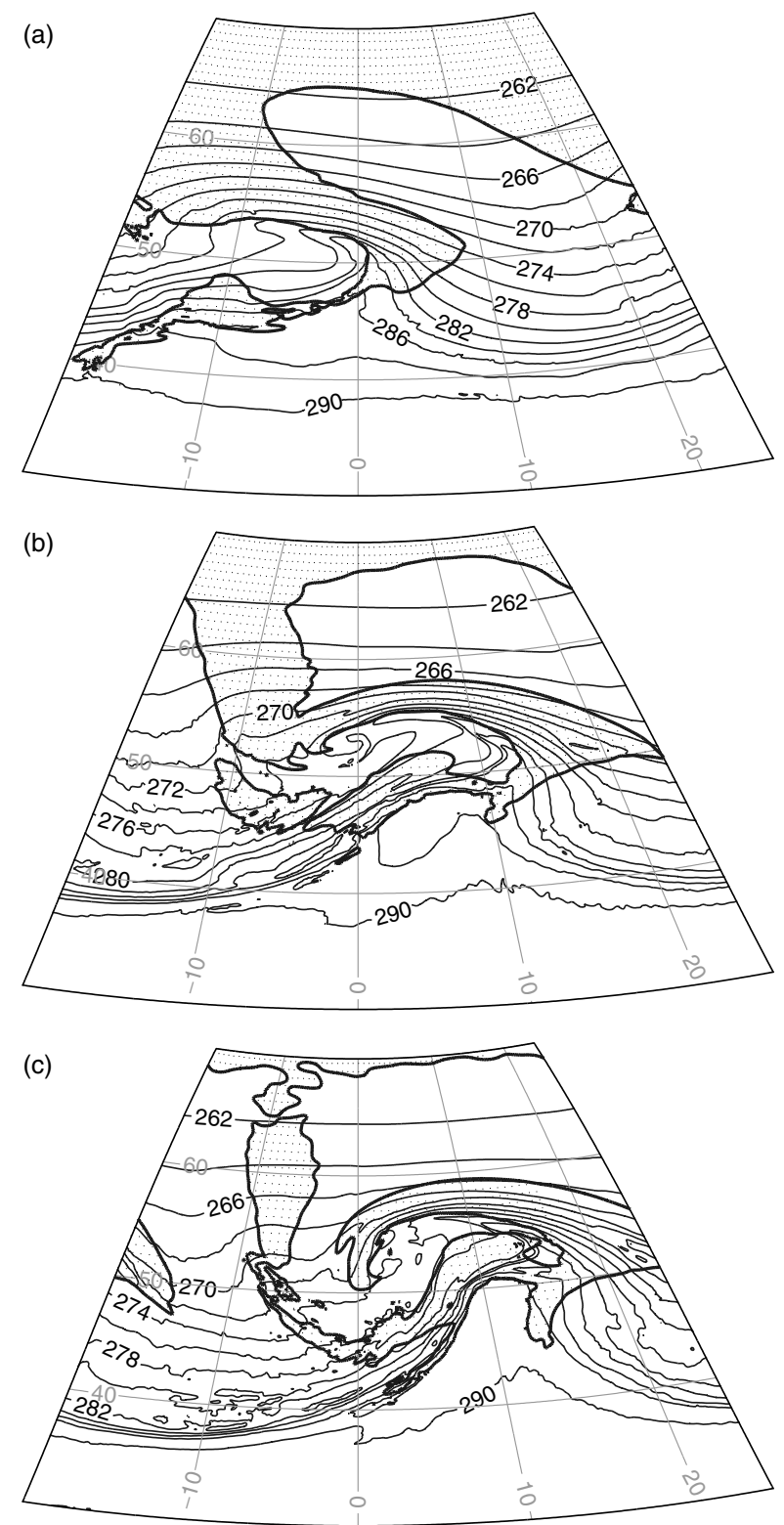

Figure 5. Moist control cyclone at Shapiro-Keyser development stages (shown on a subdomain): $\theta_{\mathrm{w}}$ at $850 \mathrm{hPa}$ (thin contours every $2 \mathrm{~K}$ ) and bold contours of $80 \% \mathrm{RH}$ at $700 \mathrm{hPa}$ with cloud regions stippled. (a) Stage II, day 2 hour 6, (b) Stage III, day 2 hour 20 and (c) Stage IV, day 3 hour 2.

in the idealised cyclone simulation is partly due to the faster movement of the cyclone in this case (system speed of $23 \mathrm{~m} \mathrm{~s}^{-1}$ compared with $9 \mathrm{~m} \mathrm{~s}^{-1}$ in the idealised case). The smaller wind maximum, to the west of the feature labelled 'sting jet' in Figure 6(d), was also found to have similar sting-jet characteristics (Baker, 2011). As with the idealised cyclone, the WCB and $\mathrm{CCB}$ have stronger wind maxima at this level (Figure 6(d)), and the part of the CCB at the tip of the cloud head has a particularly strong wind maximum of $50 \mathrm{~m} \mathrm{~s}^{-1}$. Despite its relative weakness, the local wind maximum in the idealised cyclone is still of interest since it lies in the location where sting jets are found. This feature will be termed a sting jet from now on as it will be shown to be consistent with the definition of a sting jet (section 1) by the trajectory analysis in section 3.4. A second, slightly weaker, wind maximum lies to the west of the sting jet, closer to the tip of the cloud head. 
(a)

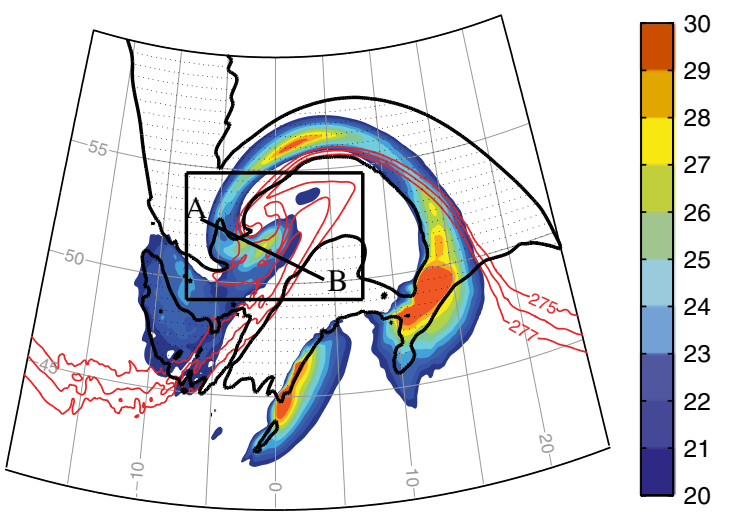

(c)

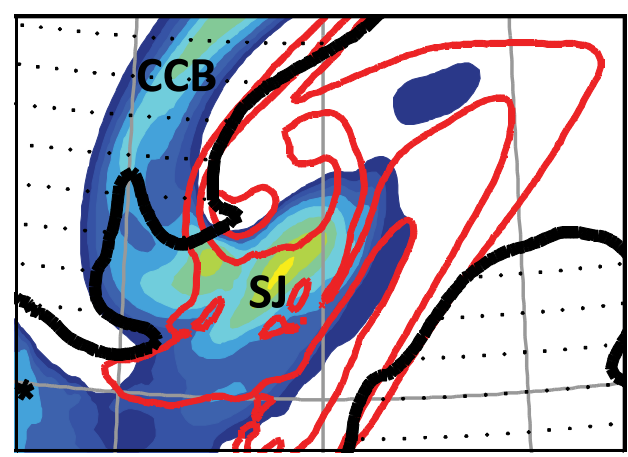

(e)

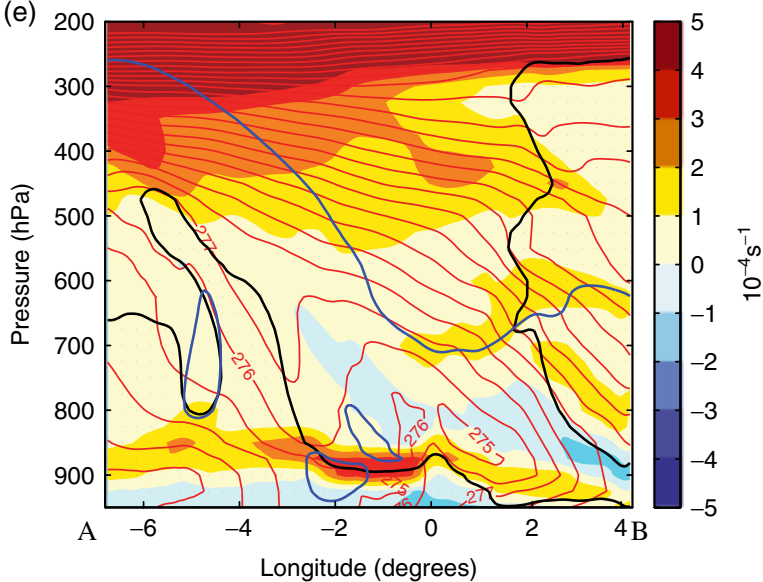

(b)

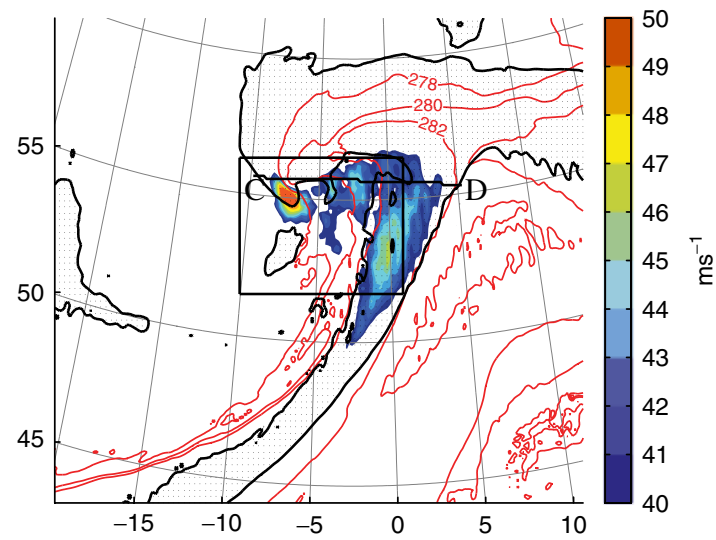

(d)
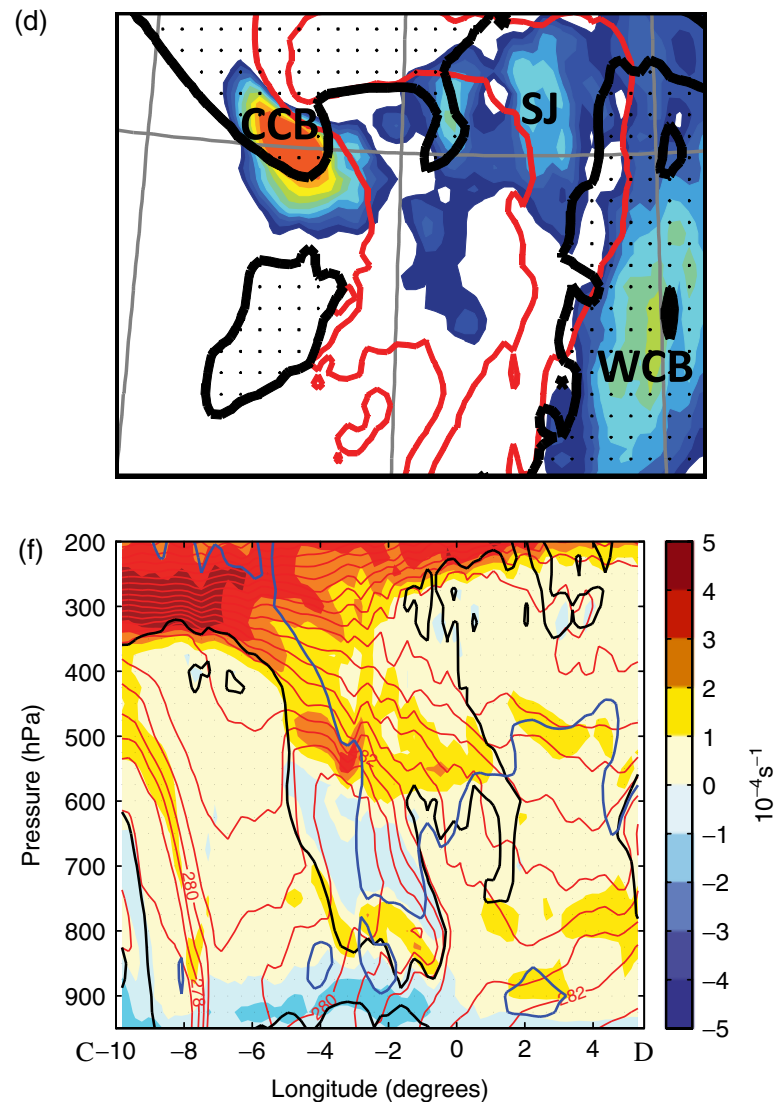

Figure 6. Sections at the time of the sting-jet low-level wind maximum for the (a, c,e) moist control cyclone at day 2 hour 20 and (b, $d$, $f$ ) for windstorm Gudrun at 0400 UTC on 8 January 2005. (a, b) Earth-relative wind strength (shading) at 850 hPa overplotted with contours of $\theta_{\mathrm{w}}$ at 850 hPa (red) and $80 \% \mathrm{RH}$ at $700 \mathrm{hPa}$ (bold black). (c, d) Close-ups of the frontal fracture regions for each case, shown by the black boxes in (a) and (b). (e, f) Vertical cross-sections through the lines A-B and C-D marked in (a) and (b), showing moist static stability (shading) with overlaid contours of $\theta_{\mathrm{w}}$ (red contours every $2 \mathrm{~K}$ ), $80 \% \mathrm{RH}$ (bold black contours) and bold blue contours showing (e) $26 \mathrm{~m} \mathrm{~s}^{-1}$ and (f) $44 \mathrm{~m} \mathrm{~s}^{-1}$ Earth-relative wind strength. Regions of cloud are shown stippled. This figure is available in colour online at wileyonlinelibrary.com/journal/qj

The vertical cross-section in Figure 6(e) shows differences in the structure and height of these two wind features in the idealised simulation. The sting-jet wind feature slopes downwards in dry air and extends between around 875 and $800 \mathrm{hPa}$. This feature lies in an area of slack $\theta_{\mathrm{w}}$ gradient, consistent with its location within the frontal fracture region. In contrast, the weaker wind maximum seen in Figure 6(c) is associated with a lower-level feature which lies below $850 \mathrm{hPa}$ within cloudy air in the boundary layer. Above the sting jet the moist static stability is negative. Below this is a layer of strongly positive moist static stability, which appears to act as a barrier preventing the sting jet from descending further. Below this is a layer of negative moist static stability above the surface. An equivalent vertical cross-section for the simulation of windstorm Gudrun is shown in Figure 6(f). In this case the sting-jet wind maximum also lies within a region of slack $\theta_{\mathrm{w}}$ gradient, extending between around 900 and $800 \mathrm{hPa}$, but is located within cloudy air. The moist static stability profile has a similar structure to the idealised case, with a region of negative moist static stability above around $800 \mathrm{hPa}$, a layer of positive moist static stability below this, and a layer of negative moist static stability above the surface. However, in this case the positive static stability layer is much weaker than in the idealised case, and the sting jet has penetrated this layer and lies below it. This difference in the strength of this stable layer affects the ability of the high-momentum sting-jet air to produce strong surface gusts. In Gudrun, model-derived $10 \mathrm{~m}$ gusts (not shown) 
have a local maximum of $32 \mathrm{~m} \mathrm{~s}^{-1}$ associated with the sting jet. In contrast, analysis of near-surface gusts in the idealised simulation (not shown) shows that there is no signature at lower levels corresponding to the sting-jet wind maximum above the boundary layer. The strongest $10 \mathrm{~m}$ gusts in both the idealised cyclone and windstorm Gudrun are associated with the CCB, particularly in the area beneath the hooked tip of the cloud head where the CCB hooks round. In the idealised cyclone, a second maximum in near-surface gusts corresponds to the lower wind maximum in Figure 6(e), which lies below the layer of positive moist static stability.

In the dry cyclone (not shown), the frontal fracture is less distinct and there is no associated local wind maximum at the top of the boundary layer that could be attributed to a sting jet. This result is expected since the dry model cannot generate moist instabilities; it therefore should not produce a sting jet. As in the moist cyclone, the maximum winds at this level in the dry cyclone are associated with the leading edge of the CCB and the WCB. Consequently, the strongest near-surface gusts are associated with the CCB.

\subsection{Trajectory analysis}

Trajectories were computed back $12 \mathrm{~h}$ from the frontal fracture region in the moist control cyclone to determine the origin of the air associated with the strong winds. Only trajectories terminating in the specified region with wind speed greater than $26 \mathrm{~m} \mathrm{~s}^{-1}$ and which experienced a pressure increase of at least $70 \mathrm{hPa}$ in $12 \mathrm{~h}$ were selected. These values were chosen to give a reasonable number of trajectory members. The computed trajectories (described below) show that this wind maximum is associated with air originating at mid-levels within the cloud head, consistent with a sting jet. By contrast, trajectories back from the frontal fracture region in the dry cyclone experience very weak descent towards the frontal fracture region (descending $51 \mathrm{hPa}$ in $12 \mathrm{~h}$, corresponding to a descent rate on average a quarter of the descent rate of the sting jet in the moist control run - see below). This supports the hypothesis that the sting jet exists due to moist processes and therefore cannot occur in a dry cyclone.

The sting-jet trajectories originate within the cloud head (Figure $7(\mathrm{a})$ ), ascending to a minimum pressure of $687 \mathrm{hPa}$ before beginning their descent at day 2 hour 12 (Figure 8(a)). The trajectories undergo a reduction in $\mathrm{RH}$ and accelerate during descent (Figures 8(b,c)), consistent with the sting-jet definition given in section 1 . The descent rate, acceleration and change in $\mathrm{RH}$ are very similar in the idealised simulation and windstorm Gudrun (Figures $8(\mathrm{a}-\mathrm{c})$ ), although the sting jet in Gudrun originates around $100 \mathrm{hPa}$ higher than the sting jet in the idealised cyclone, and has consistently stronger wind speeds. In both cases, $\theta_{\mathrm{w}}$ is approximately conserved along trajectories (Figure $8(\mathrm{~d})$ ); note that the sharp increase in $\theta_{\mathrm{w}}$ in the last hour of the Gudrun trajectories is due to mixing as the trajectories enter the boundary layer.

Figure 7 also shows the number of mid-level pressure levels satisfying the criteria for the $\mathrm{MPV}^{*}$-based CSI diagnostic described in section 2.5. The sting-jet trajectories start their descent from the southern edge of a region of the cloud head with a large concentration of CSI points (Figure $7(\mathrm{a})$ ). The number of CSI points in this part of the cloud head reduces after the trajectories leave this region (Figures $7(\mathrm{~b}, \mathrm{c})$ ). This suggests that CSI is being released here. This reduction in CSI in the cloud head (a)
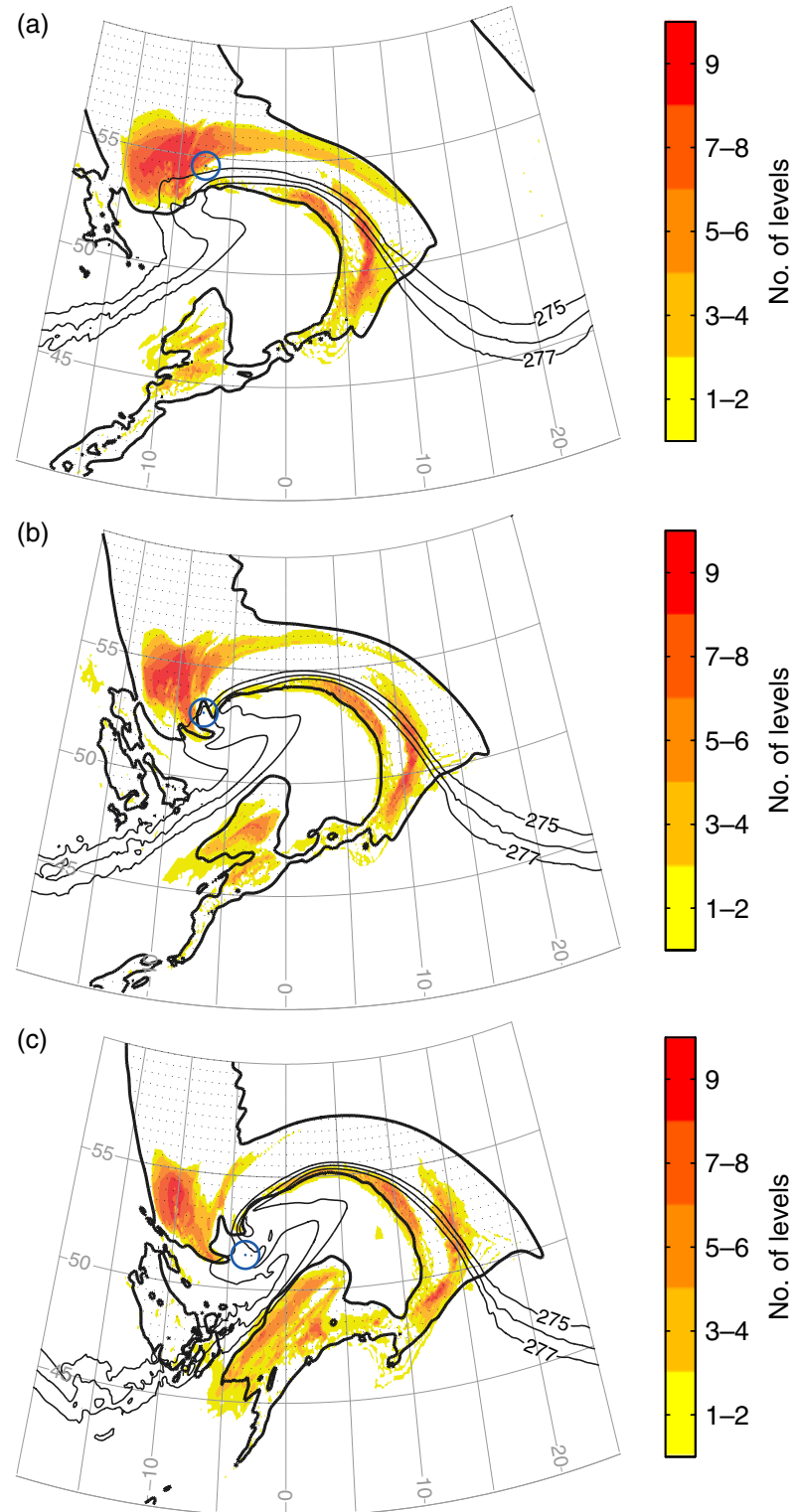

Figure 7. Number of pressure levels (shading) between 800 and $600 \mathrm{hPa}$ (of a total of nine levels) satisfying the criteria for CSI as determined by the MPV*-based diagnostic. Overplotted contours are $\theta_{\mathrm{w}}$ (thin contours at $275 \mathrm{~K}, 276 \mathrm{~K}$ and $277 \mathrm{~K}$ ) at $850 \mathrm{hPa}$, and $\mathrm{RH}$ (bold contours at $80 \%$ ) at $700 \mathrm{hPa}$, with regions of cloud shown stippled. Circles show the positions of the sting-jet trajectories; circles are centred at the position of the ensemble mean. Times shown are (a) day 2 hour 10 (corresponding to hour -10 in Figure 8), (b) day 2 hour 14 (corresponding to hour -6 in Figure 8 ), and (c) day 2 hour 18 (corresponding to hour -2 in Figure 8 ). This figure is available in colour online at wileyonlinelibrary.com/journal/qj

is consistent with the observed cases analysed in Gray et al. (2011). The sting-jet trajectories initially have mean zero $\mathrm{MPV}^{*}$ (Figure $8(\mathrm{~g})$ ). At this time the trajectories are located on the southern edge of the region of CSI points in the cloud head (Figure 7(a)). Once the trajectories start to descend, at day 2 hour $12, \mathrm{MPV}^{*}$ becomes negative (Figure $8(\mathrm{~g})$ ) and remains negative for the remainder of their descent. About $2 \mathrm{~h}$ later, when the trajectories leave the cloud head, the moist static stability becomes negative as the trajectories enter a region of negative moist static stability in the dry region ahead of the cloudhead tip (equivalent to the region of negative moist static stability in the vertical cross-section in Figure 6(e) but $6 \mathrm{~h}$ earlier). 

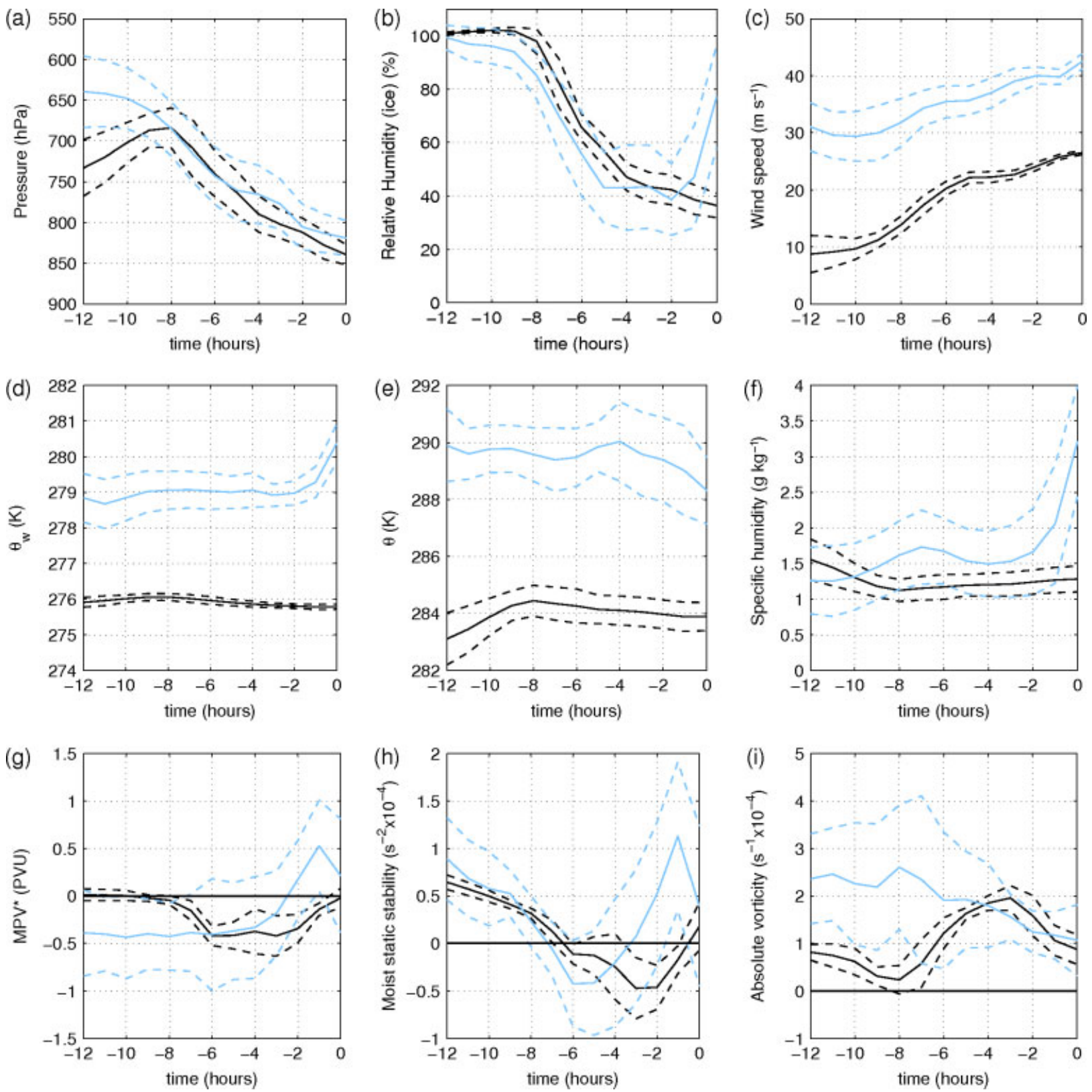

Figure 8. Timeseries of nine variables along back-trajectories for the idealised control simulation (black) and windstorm Gudrun (grey, blue online) The times shown are relative to the time of the sting jet wind maximum (day 2 hour 20 for the idealised simulation and 0400 UTC on 8 January 2005 for windstorm Gudrun). Lines show the mean (solid) and mean plus and minus one standard deviation (dashed) of the trajectory ensemble. This figure is available in colour online at wileyonlinelibrary.com/journal/qj

The sting-jet trajectories originate in cloudy air and leave the cloud head before descending through drier air, with a corresponding decrease in $\mathrm{RH}$ (Figure 8(b)). Browning (2004) hypothesized that evaporation at the tip of the cloud head may be important in intensifying the descent of the sting jet, and this would be indicated by a decrease in potential temperature $(\theta)$ and an increase in specific humidity $(q)$, assuming $\theta_{\mathrm{w}}$ remains constant. The ensemble mean $\theta$ and $q$ of the sting-jet trajectories in both the idealised simulation and the simulated windstorm Gudrun show small changes with time during descent prior to the trajectories in Gudrun entering the boundary layer (Figures $8(\mathrm{e}, \mathrm{f})$ ). While these changes are smaller than the standard deviation of the ensemble, Figure 9 shows that, in the idealised simulation, all of the trajectories have a decrease in $\theta$ and increase in $q$ during descent. The most rapidly descending trajectories tend to have the largest potential cooling rate, but not necessarily the largest increase in $q$. Equivalent plots for windstorm Gudrun (not shown) show larger changes in $\theta$ and $q$ over the same amount of time for the trajectories descending the most (reduction in $\theta$ up to $3 \mathrm{~K}$ compared with around $1 \mathrm{~K}$ in the idealised simulation, and increase in $q$ up to $2 \mathrm{~g} \mathrm{~kg}^{-1}$ compared with less than $\left.0.4 \mathrm{~g} \mathrm{~kg}^{-1}\right)$. However, some of the trajectories in Gudrun with the smallest change in pressure show an increase in $\theta$ and a decrease in $q$. Similar behaviour is seen for $\theta$ in the Great Storm (Clark et al. (2005), Figure 12), with the trajectories descending the most associated with potential cooling of over $5 \mathrm{~K}$, but those descending the least associated with potential warming of up to $5 \mathrm{~K}$.

The second local maximum in wind strength, to the west of the sting-jet region, is not associated with descending air. Trajectory analysis (not shown) shows that this air originates at low levels (mean pressure $950 \mathrm{hPa}$ at day 2 

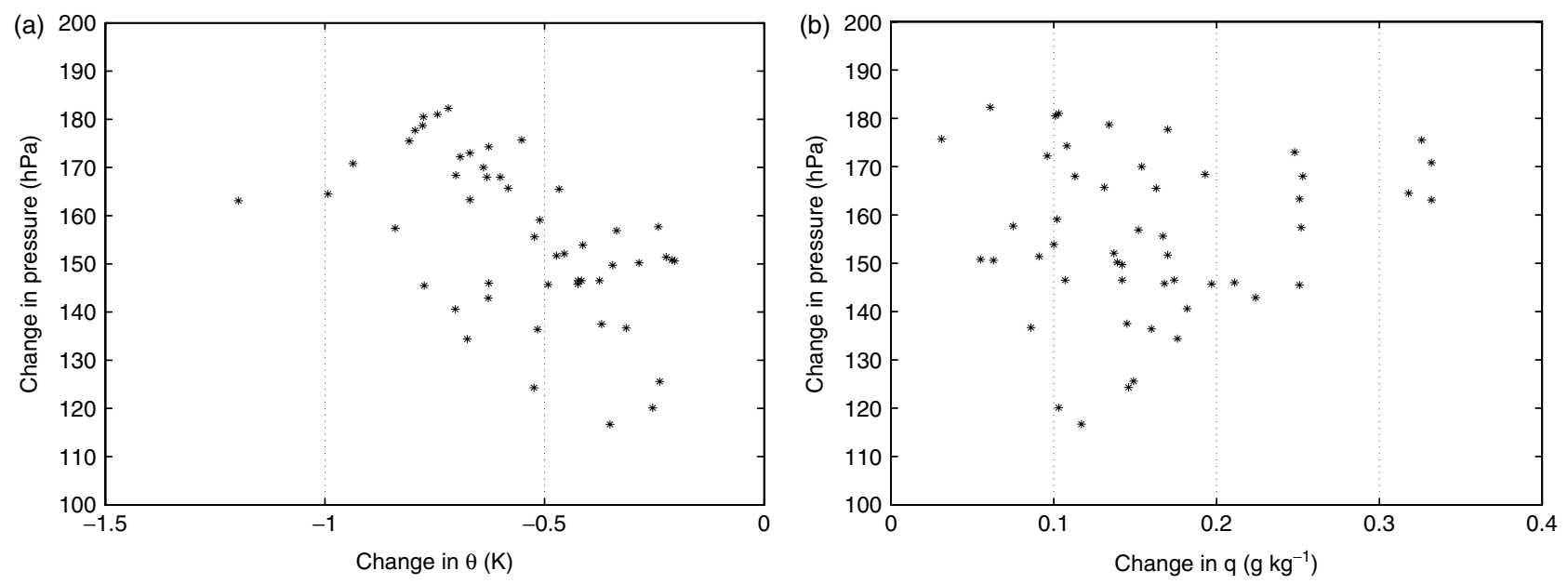

Figure 9. Scatterplots of change in pressure against (a) change in $\theta$ and (b) change in $q$ between day 2 hour 12 and day 2 hour 20 (during the time that the trajectories were descending).

hour 8) and ascends along the warm front within the cloud head, remaining within cloudy air at all times. The path of these trajectories resembles an observed low- $\theta_{\mathrm{w}}$, ascending flow identified by Browning and Roberts (1994) as a CCB. A similar jet also occurred in windstorm Anna (a sting-jet cyclone) which was distinct from the jet identified as the sting jet by Martínez-Alvarado et al. (2010), but also from the CCB (O. Martinez-Alvarado, personal communication). $\mathrm{MPV}^{*}, \zeta$ and $N_{m}^{2}$ are positive throughout these trajectories implying that the associated air is stable.

\section{Sensitivity experiments}

As described in section 2.6, a series of sensitivity experiments was performed varying different parameters in the initial conditions. All these runs produced cyclones with sting-jet features although these features varied in maximum wind strength and descent rate. It was found that changing the initial tropospheric static stability had the greatest effect on the properties of the resulting sting jet, and we therefore only discuss these runs here. The fact that a sting jet exists in all the runs shows that it is a robust feature, and not simply an anomalous feature of the chosen control run.

\subsection{Sensitivity of the sting-jet strength to initial static stability}

Various parameters were derived from the sensitivity runs (Table 2), as described in section 2.6. These parameters are analysed here to determine how changes to the initial static stability affect the cyclone and sting jet in each case.

Figure 10 shows an increase in the peak EKE with decreasing initial tropospheric static stability $\left(N_{\text {trop }}\right)$, while the timing of the peak in EKE does not follow such a trend. Run NT25, like the control, has a second local maximum in EKE shortly before day 7; the other cases have only one peak in EKE. The cyclone growth rate derived from EKE increases with decreasing $N_{\text {trop }}$ (Figure 11(a)), as expected from the Eady growth rate equation, and indeed, this derived cyclone growth rate, $\sigma_{\mathrm{EKE}}$, corresponds well with the Eady growth rate (Table 2).

The two measures of sting-jet strength, namely $u_{\max }$ and $\Delta p / \Delta t$, are both positively correlated with $\sigma_{\mathrm{EKE}}$ (Figures $11(\mathrm{a}, \mathrm{b})$ and Table 2). The sting-jet strength is therefore related to the intensification rate of the large-scale

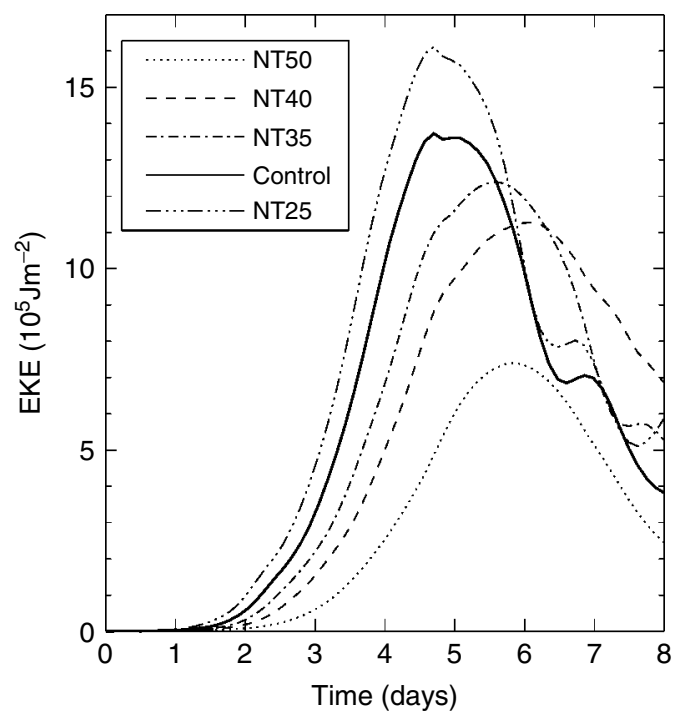

Figure 10. Time evolution of domain-averaged EKE for runs varying $N_{\text {trop. }}$.

cyclone. While $u_{\max }$ and $\Delta p / \Delta t$ are positively correlated, they are not linearly related (Figure $11(\mathrm{c})$ ). There is a sharp increase in $\Delta p / \Delta t$ between NT35 and the control. This suggests that the jets formed in the runs with the lowest initial state static stability may be fundamentally different to those forming in the runs with higher initial state static stability. Trajectory analysis of NT35 (not shown) and NT40 (Figure 12(h)) shows that moist static stability in these cases is positive during the sting jet's descent. In contrast, trajectories for the control (Figure $8(\mathrm{~h})$ ) and case NT25 (Figure 12(h)) show that the moist static stability becomes negative as the jet descends.

There is no direct relationship between $u_{\max }$ and $u_{\mathrm{CCB}}$ (Figure 11(d)), i.e. between the strengths of the sting jet and CCB. This emphasises that the sting jet is distinct from the CCB and cannot be considered as an extension of the CCB into the dry air at this stage in the cyclone evolution.

\subsection{Sensitivity of sting-jet trajectory characteristics to initial static stability}

For the purposes of comparing the properties of the sting jet in each case, sting-jet trajectories were calculated as 

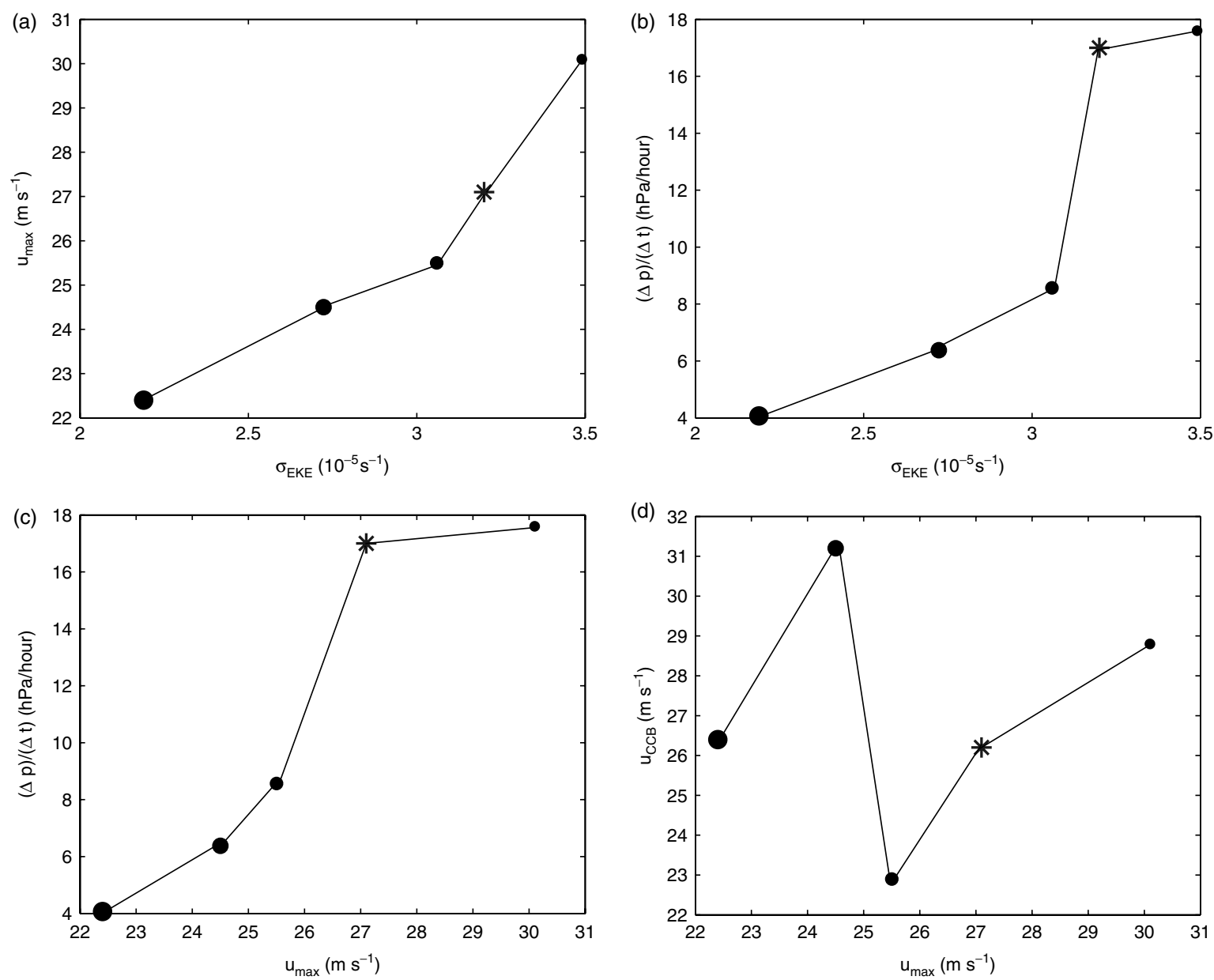

Figure 11. (a) Frontal fracture wind maximum plotted against $\sigma_{\mathrm{EKE}}$, (b) sting-jet descent rate against $\sigma_{\mathrm{EKE}}$, (c) sting-jet descent rate against the frontal fracture wind maximum, and (d) CCB wind maximum against the frontal fracture wind maximum. The star indicates the control run and increasing circle sizes correspond to increasing $N_{\text {trop }}$.

Table 2. Results from the sensitivity runs.

\begin{tabular}{lccccc}
\hline Run name & $\begin{array}{c}\sigma_{\text {EKE }} \\
\left(10^{-5} \mathrm{~s}^{-1}\right)\end{array}$ & $\begin{array}{c}\sigma_{\text {Eady }} \\
\left(10^{-5} \mathrm{~s}^{-1}\right)\end{array}$ & $\begin{array}{c}\text { Time of } u_{\max } \\
(\text { day, hour })\end{array}$ & $\begin{array}{c}\Delta p / \Delta t \\
\left(10^{-2} \mathrm{~Pa} \mathrm{~s}^{-1}\right)\end{array}$ & $\begin{array}{c}u_{\mathrm{CCB}} \\
\left(\mathrm{m} \mathrm{s}^{-1}\right)\end{array}$ \\
\hline NT50 & 1.20 & 1.09 & 3,17 & 11.3 & 22.4 \\
NT40 & 1.34 & 1.36 & 3,9 & 26.9 & 23.8 \\
NT35 & 1.44 & 1.53 & 3,0 & 47.2 & 25.5 \\
Control & 1.55 & 1.60 & 2,20 & 48.9 & 22.9 \\
NT25 & 1.69 & 1.75 & 2,14 & 26.9 & 30.1 \\
\hline
\end{tabular}

in the control run, taken back from the region of strong winds in the frontal fracture zone at the time of the largest maximum wind speed corresponding to this region. Equivalent selection criteria were applied for all cases, but with the wind speed threshold, pressure change and time period chosen to be appropriate for each case. The wind speed threshold in each case was chosen to be around $1 \mathrm{~m} \mathrm{~s}^{-1}$ less than the wind maximum in the frontal fracture region, while the pressure change and time period were chosen to ensure that a consistent number of trajectory ensemble members was obtained (ranging between 33 and $50)$.

Here we compare cases NT25 and NT40 (with reduced and increased $N_{\text {trop }}$ compared to the control, respectively) to determine the mechanisms that govern the descent rate of the sting jet.
The cyclone in run NT40 develops more slowly than the control cyclone whereas the cyclone in run NT25 develops faster (Table 2). In case NT40, the sting jet descends much more slowly than the sting jet in the control cyclone, and originates at a lower level (mean pressure $714 \mathrm{hPa}$ at the start of descent, compared to $684 \mathrm{hPa}$ in the control; Figure 12(a)). In contrast, the sting jet in case NT25 descends more rapidly, with a period of particularly rapid descent between day 2 hour 9 and day 2 hour 13 (Figure 12(a)). Both cases show a decrease in $\mathrm{RH}$ to around $45 \%$ during the period of descent (Figure 12(b)). Case NT25 shows a much larger increase in wind speed during descent than case NT40 or the control (Figure 12(c)). In both cases $\theta_{\mathrm{w}}$ is well conserved (Figure 12(d)), and while case NT40 shows no discernable change in $\theta$ or $q$ (Figures $12(\mathrm{e}, \mathrm{f})$ ), case NT25 shows larger cooling and moistening, respectively, in these quantities during descent than in the control case. This 

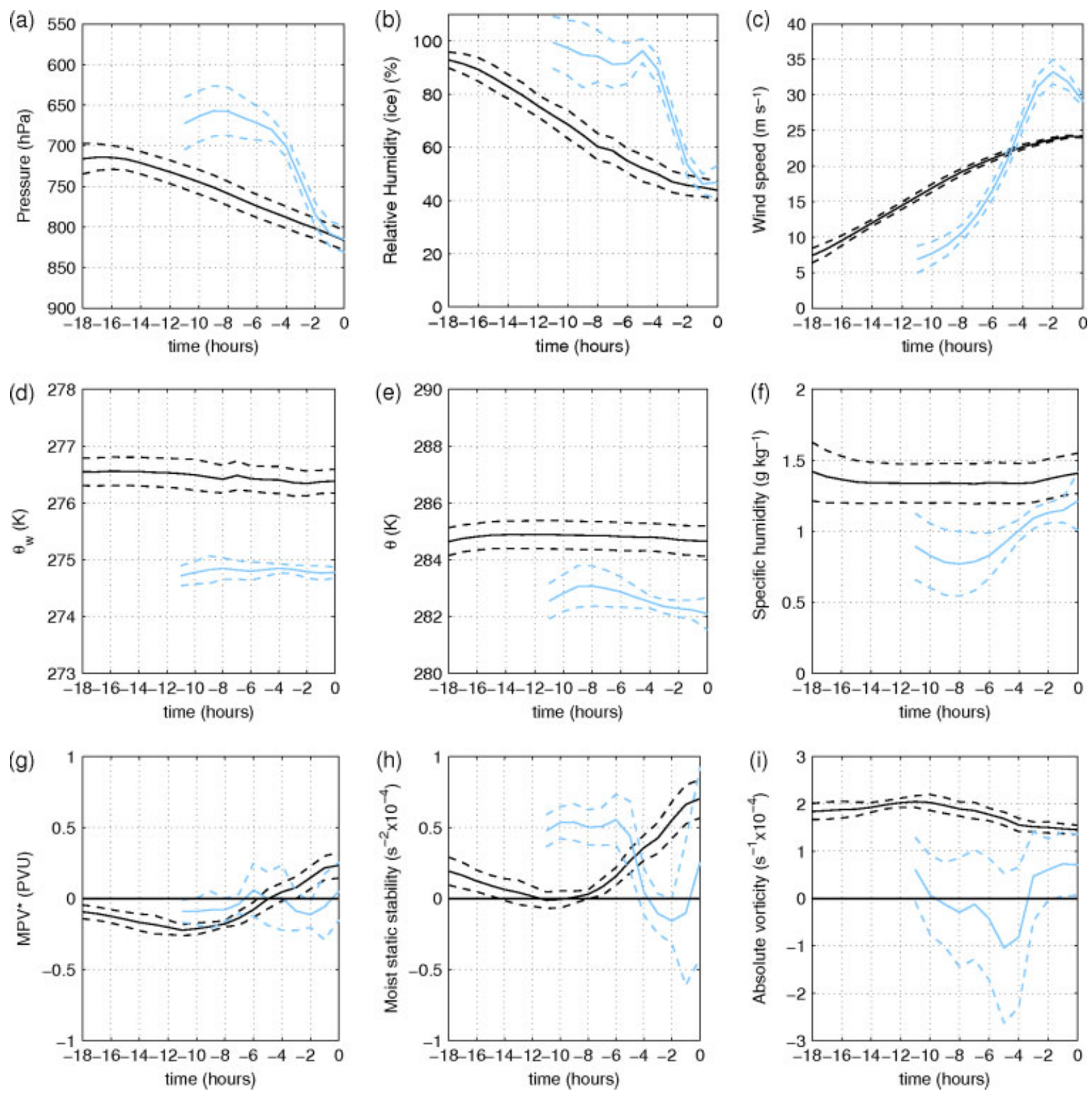

Figure 12. Timeseries of nine variables along back-trajectories in runs NT40 (black) and NT25 (grey, blue online). The times shown are relative to the time of the sting jet wind maximum (day 3 hour 9 for case NT40 and day 2 hour 14 for case NT25). Lines show the mean (solid) and mean plus and minus one standard deviation (dashed) of the trajectory ensemble. This figure is available in colour online at wileyonlinelibrary.com/journal/qj

indicates more substantial evaporative cooling which could have a role in causing the enhanced descent in this case.

The sting-jet trajectories reveal differences in the local stability of the atmosphere in each case. In case NT40, $\mathrm{MPV}^{*}$ is negative during most of the period that the sting jet descends, and becomes positive at day 3 hour 4 (Figure $12(\mathrm{~g})$ ). The ensemble means of both $N_{m}^{2}$ and $\zeta$ remain positive throughout the period of descent (Figures 12(h, i)), implying that CSI exists. In case NT25, the trajectories show a similar evolution of $\mathrm{MPV}^{*}$ and $N_{m}^{2}$ to the control case, but the ensemble becomes much less conditionally unstable (Figures $12(\mathrm{~g}, \mathrm{~h})$ ). This could either indicate that less conditional instability $(\mathrm{CI})$ is generated or that it is being released during descent. Since RH is still around $90 \%$ when $N_{m}^{2}$ becomes negative (Figure 12(b)), it is likely that $\mathrm{CI}$ is being released here. Unlike in the control case, the mean $\zeta$ of trajectories is negative from day 2 hour 4 until the trajectories leave the cloud head at around day 2 hour 10 (Figure 12(i)). This negative $\zeta$ indicates that these trajectories are inertially unstable. It is concluded that, in this case, inertial instability release has a role in transporting the sting-jet air to the tip of the cloud head, and from there the jet descends within a region of weakly negative $N_{m}^{2}$. The faster descent of the jet in this case compared to that in the control could be due to more substantial evaporative cooling and the release of CI.

\subsection{The role of evaporation}

In the two cases with the most rapidly descending sting jets (the control and NT25), the sting-jet trajectories show some evidence of evaporative cooling occurring during their descent. The control simulation was repeated with evaporation of melting snow and rain turned off $2 \mathrm{~h}$ before the sting jet started to descend (i.e. at day 2 hour 10). This had no significant impact on the properties of the sting 
jet (not shown). The associated maximum wind strength in the frontal fracture region was unchanged, and the jet descended at the same rate as in the control simulation. The moist static stability of the trajectories during the last $6 \mathrm{~h}$ of descent was more strongly negative than in the control case, and a vertical cross-section equivalent to Figure 6(e) (not shown) showed a region of slightly more negative moist static stability above the sting jet than in the control. From this we cannot conclude whether or not evaporation is an important mechanism in driving or enhancing the sting jet's descent. We hypothesize that the decrease in the stability of the air through which the sting jet descends has counteracted any effect of the reduced evaporation on the descent rate.

\section{Conclusions and discussion}

High-resolution simulations of idealised sting-jet cyclones have been presented. The set-up used was based on that of the LC1 simulations of Thorncroft et al. (1993) with the addition of moisture and a boundary layer and with additional modifications to produce cyclones more similar to observed sting-jet cyclones. While these changes made the resulting jet structure more similar to the background state of the observed cyclone, there were some differences in the low-level temperature structure resulting in lower surface temperatures in the midlatitudes. The lower temperatures are likely to have reduced the amount of available moisture, resulting in less cloud formation within the cyclone. Despite these differences, the idealised cyclone still produced a sting-jet feature.

The large-scale development of the moist control cyclone was consistent with the Shapiro-Keyser cyclone development model, with frontal fracture occurring at day 2 hour 6 of the simulation. The sting jet was identified at Stage III of the development, consistent with the timing of observed sting jets. A dry simulation produced a cyclone with similar large-scale development but which did not contain a sting jet.

The sting jet was identified as a local wind maximum above the top of the boundary layer, within the frontal fracture region. Trajectory analysis revealed that the associated air originated within the cloud head and descended into the frontal fracture region, with characteristics consistent with a sting jet. Comparison with the sting jet in windstorm Gudrun showed similarities in descent, acceleration and drying rates. The sting jet in windstorm Gudrun had a consistently higher wind speed, although this was partly due to the higher system velocity of the windstorm compared to the idealised cyclone. In both the idealised cyclone and windstorm Gudrun, the sting-jet wind maximum at the top of the boundary layer was weaker than that of the CCB and WCB at this level. The sting jet in the idealised cyclone was located above a region of positive moist static stability, which could prevent downward transport of the high-momentum air to the surface, and thus prevent strong surface winds and gusts from occurring. In contrast, the sting jet in windstorm Gudrun had penetrated below a layer of positive moist static stability into a region of negative moist static stability, allowing downward momentum transport and resulting in strong near-surface gusts.

A sensitivity analysis of the moist control simulation performed by changing the initial state tropospheric static stability, stratospheric static stability and upper-level jet strength revealed that the existence of the sting jet was robust to these changes as it existed in all cases. The strength, descent rate and time of occurrence of the sting jet varied between cases. Changing the initial tropospheric static stability was found to have the greatest effect on the strength and descent rate of the resulting sting jet, and therefore only these experiments were discussed here. A marked enhancement of the descent rate of the sting jet as the initial state static stability reduced from run NT35 to the control suggests different sting-jet behaviour.

All cases showed some evidence that CSI release played a role in the sting jet. In the moist control cyclone, there was a region of CSI in the west part of the cloud head, where the sting jet originated, and evidence that the instability was released as the sting jet descended. This is consistent with similar behaviour in observed sting-jet cases (Gray et al., 2011). The sting-jet trajectories had near-zero or negative $\mathrm{MPV}^{*}$ throughout the descent. Negative MPV* of the trajectories after leaving the cloud head was associated with entering a region of negative moist static stability. In a case with stronger initial static stability (in which the resulting sting jet was weaker and descended more slowly), negative $\mathrm{MPV}^{*}$ during most of the period of the sting jet's descent, and positive $N_{m}^{2}$ and $\zeta$ indicated the presence of CSI. In contrast, a case with lower initial static stability (resulting in a stronger, more rapidly descending sting jet) had negative $\zeta$ while the sting jet was in the cloud head, indicating that inertial instability release had a role in the sting jet in this case.

In the two cases with the most rapidly descending sting jets (the control simulation and case NT25), the region through which the sting jet descended ahead of the cloudhead tip was characterised by negative moist static stability. In the control case the air here was dry, so CI release is unlikely to have occurred. However in case NT25, the stingjet trajectories were still close to saturation in the first few hours of descent, so it is likely that CI was released here. In both these cases, the sting-jet trajectories showed evidence of evaporative cooling during descent. In other cases the amount of evaporative cooling was much less. A simulation was performed with evaporative cooling turned off from the start of the sting jet's descent. This had no effect on the strength or descent rate of the sting jet, implying that evaporation did not have a significant effect in this case. However, turning off evaporation also had the effect of decreasing the stability of the air through which the sting jet descended. We hypothesize that this counteracted any reduction in descent rate that occurred due to the lack of evaporation.

The robustness of the existence of a sting jet in the idealised moist simulations indicates that sting jets could be a ubiquitous feature of Shapiro-Keyser-type cyclones. However, the failure of these sting jets to penetrate a layer of strong moist static stability, and so reach the surface, suggests that sting jets may frequently produce less damaging surface winds than the WCB and CCB. We have defined the sting jet here independently of a driving mechanism although previous studies have implicated evaporative cooling and the release of conditional symmetric instability. There is evidence of the release of all three atmospheric instabilities associated with negative saturated moist potential vorticity in the sting jets simulated here. In addition to conditional symmetric instability, the release of inertial and conditional instability are also indicated, although only strongly in the case with weakest initial static stability; evaporative cooling was found 
to occur in the runs with weaker initial static stability but was not found to have a significant effect on sting-jet strength. Whilst some caution should be applied in generalising these idealised results to typical sting-jet cyclones due to the limitations of the idealised initial state, we conclude that, in addition to the previously identified mechanisms of CSI release and evaporative cooling, the potential exists for release of conditional and inertial instability to cause or contribute to the generation of sting jets.

\section{Acknowledgements}

We thank the Met Office for making the MetUM available and the Natural Environment Research Council (NERC) National Centre for Atmospheric Science Computational Modelling Services for providing computing and technical support. The project was funded by NERC (grant reference NE/E004415/1). LHB would also like to thank the Met Office for financial support through a CASE studentship.

\section{References}

Baker LH. 2009. Sting jets in severe Northern European wind storms. Weather 64: 143-148.

Baker LH. 2011. 'Sting jets in extratropical cyclones'. PhD thesis University of Reading: UK.

Balasubramanian G, Garner ST. 1997. The role of momentum fluxes in shaping the life cycle of a baroclinic wave. J. Atmos. Sci. 54: 510-533.

Beare RJ. 2007. Boundary layer mechanisms in extratropical cyclones. Q. J. R. Meteorol. Soc. 133: 503-515.

Bennetts DA, Hoskins BJ. 1979. Conditional symmetric instability - a possible explanation for frontal rainbands. Q. J. R. Meteorol. Soc. 105: 945-962.

Bjerknes J, Solberg H. 1922. Life cycle of cyclones and the polar front theory of atmospheric circulation. Geofys. Publ. 3: 3-18.

Boutle IA, Beare RJ, Belcher SE, Brown AR, Plant RS. 2010. The moist boundary layer under a mid-latitude weather system. Boundary-Layer Meteorol. 134: 367-386.

Browning KA. 2004. The sting at the end of the tail: Damaging winds associated with extratropical cyclones. Q. J. R. Meteorol. Soc. 130: 375-399.

Browning KA, Field M. 2004. Evidence from Meteosat imagery of the interaction of sting jets with the boundary layer. Meteorol. Appl. 11 $277-289$.

Browning KA, Roberts NM. 1994. Structure of a frontal cyclone. Q. J. R. Meteorol. Soc. 120: 1535-1557.

Cao Z. 2009. The sting jet in a simulated extratropical cyclone. Open Atmos. Sci. J. 3: 212-218.

Clark PA, Browning KA, Wang C. 2005. The sting at the end of the tail: Model diagnostics of fine-scale three-dimensional structure of the cloud head. Q. J. R. Meteorol. Soc. 131: 2263-2292.

Davies T, Cullen MJP, Malcolm AJ, Mawson MH, Staniforth A, White AA, Wood N. 2005. A new dynamical core for the Met Office's global and regional modelling of the atmosphere. Q. J. R. Meteorol. Soc. 131: 1759-1782.

Durran DR, Klemp JB. 1982. On the effects of moisture on the Brunt-Väisälä frequency. J. Atmos. Sci. 39: 2152-2158.

Edwards JM, Slingo A. 1996. Studies with a flexible new radiation code. I: Choosing a configuration for a large-scale model. Q. J. R. Meteorol. Soc. 122: 689-719.

Emanuel KA. 1983a. The Lagrangian parcel dynamics of moist symmetric instability. J. Atmos. Sci. 40: 2368-2376.
Emanuel KA. 1983b. On assessing local conditional symmetric instability from atmospheric soundings. Mon. Weather Rev. 111: 2016-2033.

Gray SL, Thorpe AJ. 2001. Parcel theory in three dimensions and the calculation of SCAPE. Mon. Weather Rev. 129: 1656-1672.

Gray SL, Martínez-Alvarado O, Baker LH, Clark PA. 2011. Conditional symmetric instability in sting-jet storms. Q. J. R. Meteorol. Soc. 137: 1482-1500.

Gregory D, Rowntree PR. 1990. A mass flux convection scheme with representation of cloud ensemble characteristics and stabilitydependent closure. Mon. Weather Rev. 118: 1483-1506.

Lock AP, Brown AR, Bush MR, Martin GM, Smith RNB. 2000. A new boundary-layer mixing scheme. Part I: scheme description and single-column model tests. Mon. Weather Rev. 128: 3187-3199.

Martinez-Alvarado O, Weidle F, Gray SL. 2010. Sting jets in simulations of a real cyclone by two mesoscale models. Mon. Weather Rev. 138: 4054-4075

Martínez-Alvarado O, Gray SL, Clark PA, Baker LH. 2011. Objective detection of sting jets in low-resolution datasets. Meteorol. Appl. in press, DOI: 10.1002/met.297.

Martínez-Alvarado O, Gray SL, Catto JL, Clark PA. 2012. Sting jets in intense winter North-Atlantic windstorms. Environ. Res. Lett. 7: DOI: 10.1088/1748-9326/7/2/024014.

Novak DR, Bosart LF, Keyser D, Waldstreicher JS. 2004. An observational study of cold season-banded precipitation in northeast US cyclones. Weather and Forecasting 19: 993-1010.

Parton GA, Vaughan G, Norton EG, Browning KA, Clark PA. 2009. Wind profiler observations of a sting jet. Q. J. R. Meteorol. Soc. 135: 663-680.

Parton GA, Dore A, Vaughan G. 2010. A climatology of mid-tropospheric mesoscale strong wind events as observed by the MST radar, Aberystwyth. Meteorol. Appl. 17: 340-354.

Persson POG, Warner TT. 1993. Nonlinear hydrostatic conditional symmetric instability: Implications for numerical weather prediction. Mon. Weather Rev. 121: 1821-1833.

Polvani LM, Esler JG. 2007. Transport and mixing of chemical air masses in idealised baroclinic life cycles. J. Geophys. Res. 112.

Schultz DM, Schumacher PN. 1999. The use and misuse of Conditional Symmetric Instability. Mon. Weather Rev. 127: 2709-2732.

Shapiro MA, Keyser D. 1990. Fronts, jet streams and the tropopause. In Extratropical cyclones: the Erik Palmén memorial volume. Newton C, Holopainen EO. (eds). 167-191. Amer. Meteorol. Soc: Boston, MA.

Shapiro MA, Wernli H, Bao J-W, Methven J, Zou X, Doyle J, Holt T, Donall-Grell E, Neiman P. 1999. A planetary-scale to mesoscale perspective of the lifecycles of extratropical cyclones: the bridge between theory and observations. In The Lifecycles of Extratropical Cyclones, Shapiro MA, Grønås S. (eds). 139-185. Amer. Meteorol. Soc: Boston, MA.

Tan Z-M, Zhang F, Rotunno R, Snyder C. 2004. Mesoscale predictability of moist baroclinic waves: experiments with parameterized convection. J. Atmos. Sci. 61: 1794-1804.

Thorncroft CD, Hoskins BJ, McIntyre ME. 1993. Two paradigms of baroclinic-wave life-cycle behaviour. Q. J. R. Meteorol. Soc. 119: $17-55$.

Thorpe AJ. 1992. 'An Appreciation of the Meteorological Research of Ernst Kleinschmidt'. JCMM Internal Report 11. University of Reading: UK.

Weisman ML, Klemp JB. 1982. The dependence of numerically simulated convective storms on vertical wind shear and buoyancy. Mon. Weather Rev. 110: 504-520.

Wernli H, Davies HC. 1997. A Lagrangian-based analysis of extratropical cyclones. I: The method and some applications. Q. J. R. Meteorol. Soc. 123: $467-489$.

Whitaker JS, Snyder C. 1993. The effects of spherical geometry on the evolution of baroclinic waves. J. Atmos. Sci. 50: 597-612.

Wilson DR, Ballard SP. 1999. A microphysically based precipitation scheme for the Meteorological Office Unified Model. Q. J. R. Meteorol. Soc. 125: 1607-1636. 